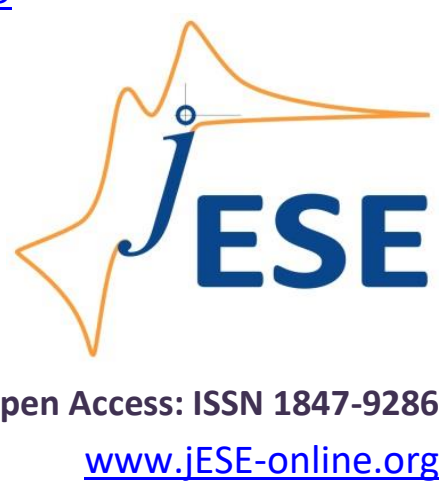

Review

\title{
Platinum utilization in proton exchange membrane fuel cell and direct methanol fuel cell
}

\author{
Madhavi Bandapati ${ }^{1}$, Sanket Goel ${ }^{2}$ and Balaji Krishnamurthy ${ }^{1, \otimes}$ \\ ${ }^{1}$ Department of Chemical Engineering, BITS-Pilani, Hyderabad Campus, Hyderabad-500078, India \\ ${ }^{2}$ Department of Electrical and Electronics Engineering, BITS-Pilani, Hyderabad Campus, Hyderabad- \\ 500078, India
}

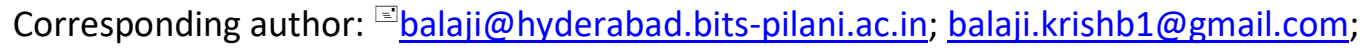

Tel.: +91-040-663-03552

Received: February 15, 2018; Revised: March 22, 2019; Accepted: March 25, 2019

\begin{abstract}
Proton exchange membrane fuel cell (PEMFC) and direct methanol fuel cell (DMFC) are increasingly used as substitutes to conventional energy systems. Their compact design, high energy density and efficient energy-conversion offer several advantages over existing energy systems with potential for use in a variety of applications. However, performance, robustness and cost are the key challenges to overcome before fuel cells can be commercialized. Even though the use of platinum (Pt) and platinum group metal (PGM) alloy catalysts provide higher performance and durability, they are at the same time the largest cost components which need to be addressed. This paper reviews different approaches adopted to enhance Pt utilization such as reducing Pt loading, decreasing Pt particle size, developing Pt free metallic alloy catalyst, improving Pt dispersion, developing membrane electrode assembly (MEA) fabrication methods, increasing mass-transport at the electrode surface and modifying the catalyst support materials. Finally, the performance optimization efforts for Pt utilization are summarized with insights into probable directions of future research in this area.
\end{abstract}

\section{Keywords}

Electrochemical active surface area; hydrogen adsorption; CO stripping; catalyst particle size; catalyst loading; catalyst dispersion; catalyst support

\section{Introduction}

Over the last two decades, proton exchange membrane fuel cell (PEMFC) and direct methanol fuel cell (DMFC) have been extensively studied and are emerging as potential systems as they provide clean energy and are commercially viable [1]. They possess a series of highly advantages features such as low operating temperature $\left(<100^{\circ} \mathrm{C}\right)$, high efficiency, sustainability at high current 
density, development of catalyst material for hydrogen generation, 10-100 fold reduction of the catalyst loading, multiple options for membrane electrode assembly (MEA) fabrication, manufacturing and synthesis process for gas diffusion layer (GDL) and membranes, development in thermal and water management, compactness, potential for low volume and weight, long stack life, fast start-up and suitability for discontinuous operation [2-4].

In the recent years, leveraging these advantages, automobile and fuel cell (FC) manufacturers are moving towards commercialization from a demonstration phase. This is carried out through development of suitable catalysts, introduction of zero emission vehicles and development of prototype vehicles that have adopted FC systems. However, several technological challenges and cost reduction still need to be overcome. The primary approaches towards addressing these challenges include reducing the precious metal catalyst loading with controlled particle deposition through improved electrode preparation methods, optimizing the MEA, enhancing the tolerance of MEA to high temperature to promote higher degrees of electro-catalysis, exploring non-platinum based electrode materials [5-7].

Platinum (Pt) or Pt-alloys such as PtRu, PtCo, PtNi, PtFe, PtV, PtMn, PtCr are the most suitable electrocatalysts for PEMFCs and DMFCs as they have low overpotential values, high catalytic activities and also ability to tolerate the harsh acidic surroundings inside FC. Pt is a less abundant and expensive noble metal that contributes as much as $50 \%$ (even at $1.7 \%$ of Pt) to the total cost of fuel cell. In addition, Pt utilization is quite low with only $25-35 \%$ utilized for electroactivity [8-10].

The limited supply and high cost of Pt necessitate its optimal utilization and reduction in $\mathrm{Pt}$ loading. Table 1 illustrates the status and long term goals set by the U.S. Department of Energy for Pt utilization with Pt loading targets. As a result, optimizing Pt utilization in order to reduce cost has been the primary focus of much research in this field [11-13].

Table 1. Platinum metal content status and targets [13]

\begin{tabular}{lccc}
\hline \multirow{2}{*}{ Characteristics } & $\mathbf{2 0 1 1}$ & \multicolumn{2}{c}{ Targets } \\
\cline { 3 - 4 } & status & $\mathbf{2 0 1 7}$ & $\mathbf{2 0 2 0}$ \\
\hline Platinum group metal (PGM) total content (both electrodes), $\mathrm{g} \mathrm{kW}^{-1}$ & 0.19 & 0.125 & 0.125 \\
\hline PGM total loading, $\mathrm{mg} \mathrm{m}^{-2}$ & 0.15 & 0.125 & 0.125 \\
\hline Loss in initial catalytic activity, wt\% & 48 & 40 & 40 \\
\hline Electrocatalyst support stability, wt\% & 10 & 10 & 10 \\
\hline Mass activity, $\mathrm{A} \mathrm{mgt}_{\mathrm{Pt}}{ }^{-1}$ & 0.24 & 0.44 & 0.44 \\
\hline Non-Pt catalyst activity per volume of supported catalyst, $\mathrm{A} \mathrm{cm}^{-3}$ & 60 & 300 & 300 \\
\hline
\end{tabular}

In order to improve Pt utilization efficiency, the electrocatalysts need to be developed with the reduced Pt loading and increased Pt active sites. The active research approaches explored towards enhancement of effective Pt utilization in PEMFC and DMFC electrodes are grouped in following categories $[14,15]$ :

- Reducing the electrocatalysts loading in fuel cell electrodes.

- Developing novel nano-structured thin-film Pt by decreasing the electrocatalysts nanoparticle size

- Reducing Pt dependence by developing metallic alloys and Pt-free electrocatalysts.

- Improving electrocatalysts dispersion by using novel fabrication methods.

- Developing MEA fabrication methods to enable better catalyst dispersion and utilization.

- Using new techniques to increase mass-transport at the fuel cell electrode surface.

- Improving the performance of carbonaceous electrocatalysts support and exploring novel noncarbonaceous electrocatalysts support materials. 
Although Pt is the catalyst commonly used for both anode and cathode in PEMFCs, the oxygen reduction reaction (ORR) at cathode is more complex with sluggish reaction kinetics, thus requiring higher Pt loading, typically several times higher than that of anode. In addition, the hydrogen oxidation reaction (HOR) on the DMFC anode catalyst suffers from high over potential. This has triggered researchers to explore optimization of Pt catalyst including the synthesis of catalysts that are more active and less expensive than Pt $[16,17]$.

This paper focuses on various approaches, already taken by researchers to optimize Pt utilization for cathode of PEMFC and both electrodes of DMFC to reduce the cost and improve the performance and durability of PEMFCs and DMFCs. Catalyst utilization can also be represented in terms of mass activity and specific activity. As catalyst utilization is a surface phenomenon [18], the progress made in this area has been presented by considering electrochemical active surface area (ECSA), as the benchmark parameter across various research approaches over a period of time. The calculation procedure of this parameter is briefly described in the following section.

In addition, fuel cell performance can also be increased by increasing specific activity of the catalyst by alloying or shaping. Specific activity (SA) is the ratio of the kinetic current to the real surface area of the catalyst. Nevertheless, in the case of nanostructures the real surface area is significantly greater than geometric and can be determined using CO stripping [21]. However, discussing specific activity of the catalyst is beyond the scope of this review.

\section{Measuring platinum utilization efficiency}

Platinum utilization (PtUt) is the amount of exposed Pt atoms available for catalytic reaction among those dispersed on the electrode. As catalyst utilization is a surface phenomenon, the surface and the specific surface area are considered as critical factors for measurement. Here, electrochemical active surface area (ECSA) is considered as a measure of Pt utilization. A comparison of ECSA with geometrical specific surface area (GSA) tells the number of electrochemically active Pt surface atoms. Therefore, the ratio of ECSA to GSA is considered as a measure of PtUt $[19,20]$.

$$
\text { PtUt, \% }=[E C S A / G S A] \times 100
$$

\section{Electrochemical active surface area (ECSA)}

ECSA is a measure of the number of electroactive Pt sites on the surface of the catalyst on which reaction occurs and is sometimes called the intrinsic Pt catalyst surface area. Numerous methods are available in the literature to calculate ECSA of Pt catalysts. In the context of this review, two primary methods, $\mathrm{H}$-adsorption $\left(\mathrm{ECSA}_{H}\right)$ and $\mathrm{CO}$ stripping $\left(\mathrm{ECSA}_{\mathrm{CO}}\right)$ used for measuring ECSA are explained below [21].

\section{$H$-adsorption $\left(E C S A_{H}\right)$}

$\mathrm{ECSA}_{H}$ of Pt catalyst, reported in $\mathrm{m}^{2} \mathrm{gPt}^{-1}$ units, is determined conventionally from hydrogen under-potential deposition (HUPD) reaction, which can be expressed as [22]:

$$
\mathrm{Pt}+\mathrm{H}^{+}+\mathrm{e}^{-} \rightleftarrows \mathrm{Pt}-\mathrm{H}_{\text {ads }}
$$

Figure 1 shows a typical hydrogen electrosorption/desorption voltammetric profile for the polycrystalline Pt electrode in $0.5 \mathrm{M} \mathrm{H}_{2} \mathrm{SO}_{4}$. Characteristic peaks between 0.0 and $\sim 0.2 \mathrm{~V}$ are attributed to the atomic hydrogen desorption/adsorption at Pt surface and ECSA $\mathrm{E}_{H}$ can be determined by:

$$
\mathrm{ECSA}_{H}=\left(100 Q_{H}\right) /\left(Q_{H(\text { ref })} m\right)
$$


In Eq. (3), $Q_{H} / \mu \mathrm{C}$ is the charge calculated by integrating the area under the cyclic voltammetry (CV) curve (Figure 1) within the potential range of hydrogen desorption, $Q_{H(r e f)}$ is the charge corresponding to formation of the monolayer of adsorbed hydrogen on the polycrystalline Pt given as $210 \mu \mathrm{C} \mathrm{cm}^{-2}$, and $m$ is the mass of Pt loading $(\mathrm{mg})$ that indicates the amount of Pt at the working electrode $[23,24]$.

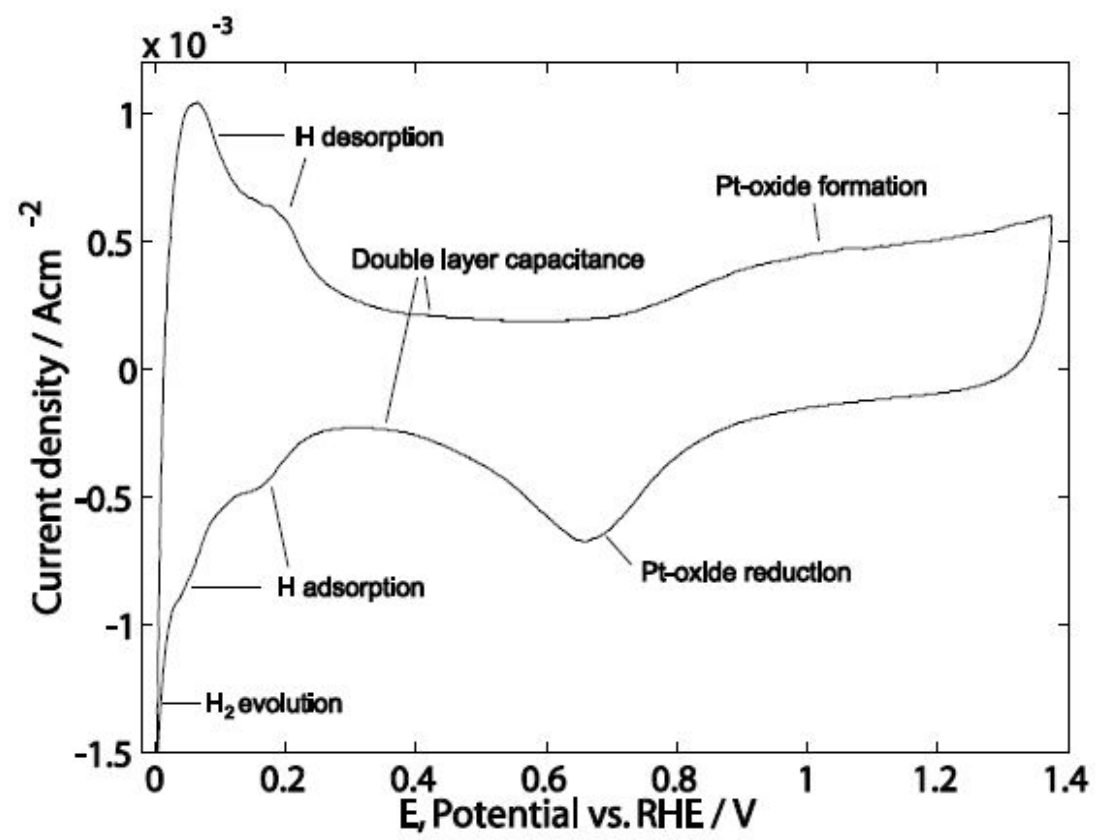

Figure 1. Typical hydrogen adsorption/desorption voltammetry profile for polycrystalline $P t$ electrode in $0.5 \mathrm{M} \mathrm{H}_{2} \mathrm{SO}_{4}$ at room temperature at $100 \mathrm{mVs}^{-1}$ [21]

When electrodes are fabricated with the polymer electrolyte membrane (PEM), however, all Pt active sites are not available for electrochemical reaction. This may be due to an improper contact of Pt particles with the solid polymer electrolyte or to electrical insulation between Pt particles caused by a thin film of the electrically non-conducting polymer electrolyte. In such case, the ECSA measured by CV in solid polymer electrolyte is denoted as ECSAMEA which is called as driven - cell mode [25]. This value may be smaller than ECSA. The ratio of ECSA and ECSAMEA is termed as MEA platinum utilization [81].

\section{CO stripping}

The most commonly used anode catalyst for DMFC is platinum-ruthenium (PtRu). The ECSA and performance of the prepared PtRu anode catalysts for DMFC are measured by means of CO stripping method.

Pre-adsorbed carbon monoxide ( $\left.\mathrm{CO}_{\mathrm{ad}}\right)$ oxidation can be calculated using $\mathrm{CO}$ adsorption removal voltammogram (Figure 2) at a particular scan rate. Gaseous $\mathrm{CO}$ can be purged into the cell to permit complete $\mathrm{CO}$ adsorption onto the electrocatalyst while maintaining a steady voltage. The surplus $\mathrm{CO}$ can be removed by nitrogen gas [26].

The following reactions occur on the platinum surface for methanol oxidation:

$$
\begin{aligned}
& \mathrm{CH}_{3} \mathrm{OH}+\mathrm{Pt} \rightarrow \mathrm{CO}_{\mathrm{ad}}-\mathrm{Pt}+4 \mathrm{H}^{+}+4 \mathrm{e}^{-} \\
& \mathrm{Pt}+\mathrm{CO}_{\mathrm{ad}}-\mathrm{Pt}+\mathrm{H}_{2} \mathrm{O} \rightarrow \mathrm{CO}_{\mathrm{ad}}-\mathrm{Pt}+\mathrm{H}^{+}+\mathrm{OH}_{\mathrm{ad}}-\mathrm{Pt}+\mathrm{e}^{-} \rightarrow 2 \mathrm{Pt}+2 \mathrm{H}^{+}+\mathrm{CO}_{2}+2 \mathrm{e}^{-}
\end{aligned}
$$

For $\mathrm{PtRu}$, the equation for methanol oxidation is as follows:

$$
\begin{aligned}
& \mathrm{CH}_{3} \mathrm{OH}+\mathrm{PtRu} \rightarrow \mathrm{CO}_{\mathrm{ad}}-\mathrm{PtRu}+4 \mathrm{e}^{-}+4 \mathrm{H}^{+} \\
& \mathrm{CO}_{\mathrm{ad}}-\mathrm{PtRu}+\mathrm{H}_{2} \mathrm{O} \rightarrow \mathrm{CO}_{\mathrm{ad}}-\mathrm{PtRu}-\mathrm{OH}_{\mathrm{ad}}+\mathrm{e}^{-}+\mathrm{H}^{+} \rightarrow \mathrm{PtRu}+\mathrm{CO}_{2}+2 \mathrm{e}^{-}+2 \mathrm{H}^{+}
\end{aligned}
$$




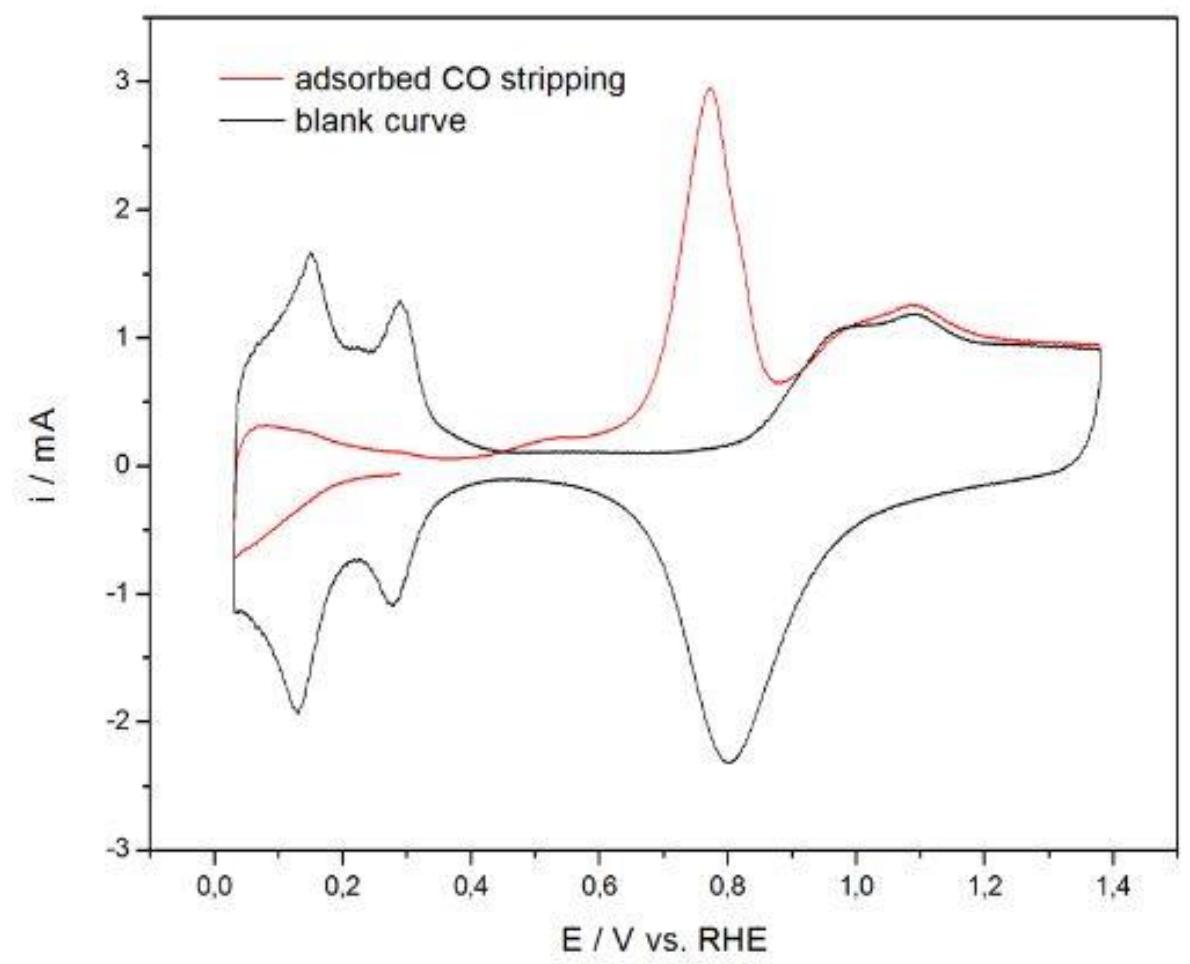

Figure 2. CO stripping current (red line) recorded at $500 \mathrm{mVs}^{-1}$ scan rate for polycrystalline Pt electrode in $0.5 \mathrm{M} \mathrm{H}_{2} \mathrm{SO}_{4}$ at $298 \mathrm{~K}$ together with a blank curve (black line). CO adsorption at $0.29 \mathrm{~V}$ vs. RHE for $20 \mathrm{~min}$ [21]

As the charge of the $\mathrm{CO}$ oxidation peak is taken as two electrons per $\mathrm{CO}$ molecule, the resulting charge is approximately double of that corresponding to the hydrogen-desorption peak. ECSAco can be calculated using the following equation:

$\mathrm{ECSA}_{\mathrm{co}}=\left(100 Q_{\mathrm{co}}\right) /\left(Q_{\mathrm{co}}(\mathrm{ref}) \mathrm{m}\right)$

In Eq. (6), $Q_{c o} / \mu C$ is the charge calculated by integrating the area under CO desorption peak, $Q_{\text {co(ref) }}$ is the charge needed for oxidation of the monolayer of adsorbed CO on the platinum surface, given as $420 \mu \mathrm{Ccm}^{-2}$, and $m$ is the mass of Pt loading $(\mathrm{mg})$ indicating the amount of platinum on the working electrode. CO stripping gives realistic ECSA on Pt-alloys, whereas ESCA based on HUPD is usually lower [27].

\section{Optimization approaches for PEMFC Cathode}

Some approaches to optimizing Pt utilization in PEMFC cathode are described below:

Reducing Pt loading and decreasing Pt particle size

Typically, the performance of a catalyst layer $(\mathrm{CL})$ has proportional relationship with the catalyst loading. However, in the case of platinum, there is a challenge of enhancing $C L$ performance while decreasing Pt loading. In order to achieve this, reducing of particle size and improving Pt dispersion on the catalyst support have been explored. As was already reported, the effective particle size of Pt based catalyst is between $2 \mathrm{~nm}$ and $4 \mathrm{~nm}$ [28]. Since the percentage of exposed Pt decreases with increase of Pt particle size, only $20-50 \%$ of total Pt is available for catalytic reaction, what is far below ideal dispersion.

Martin et al. [29] attempted to optimize electrode performance at significantly low Pt loading $\left(0.012 \mathrm{mg} \mathrm{cm}^{-2}\right.$ ) obtained by electrospray method. By optimizing control parameters (Nafion ${ }^{\circledR}$ content, flow rate for electro-spraying catalyst ink and pressure for hot pressing MEA) they could achieve high 
PtUt of $20 \mathrm{~kW} \mathrm{~g}^{-1}$ at 3.4 bar, a $70{ }^{\circ} \mathrm{C}$. This is relatively high PtUt when compared to the previous of 3.3 $\mathrm{kW} \mathrm{g}^{-1}$ [30]. Later on, the same team reported [31] further increase of PtUt to $30-35 \mathrm{~kW} \mathrm{~g}^{-1}$ at low Pt loading of $0.01 \mathrm{mg} \mathrm{cm}^{-2}$, achieved by utilizing additional benefits of a microporous layer of carbon nanotubes coated on GDL as the cathode catalyst support. The authors also observed that Pt utilization remained unchanged for $\mathrm{Nafion}^{\circledR}$ content in the range of $30-50 \%$.

Wang et al. [32] fabricated MEA with low Pt loading of $0.022 \mathrm{mg} \mathrm{cm}^{-2}$ at the cathode side by simultaneously using electrospray and electrospinning $(E / E)$ dispersion techniques, where they introduced Nafion ${ }^{\circledR}$ and Pt using two separate needles to produce Nafion ${ }^{\circledR}$ nanofibers and platinum nanoparticles (PtNP). Using this technique, they could regulate the size of fibers and loading of Pt catalyst, what resulted in improved ECSA with excellent Pt utilization of $42 \mathrm{~kW} \mathrm{~g}^{-1}$ for $\mathrm{H}_{2} / \mathrm{O}_{2}$ electrode at $0.022 \mathrm{mg} \mathrm{cm}^{-2} \mathrm{Pt}$ cathode loading.

Alia et al. [33] developed a novel electrocatalyst using Pt/Pt alloy nanotubes (PtNT) and carried out voltammetry measurements for every 6000 cycles to investigate durability and ORR activity. They found that the electrode with cathode loading of $0.04 \mathrm{mg} \mathrm{cm}^{-2}$ showed highest ECSA of $23.9 \mathrm{~m}^{2}$ $\mathrm{g}^{-1}$ with $127 \%$ PtUt (Eq. 1) for which electrode porosity was stated as the reason.

Su et al. [34] combined ultrasonic spray coating technique and catalyst coated substrate (CCS) to achieve low Pt loaded gas diffusion electrodes (GDE). Four electrode samples with varying Pt loading (between 0.138 and $1.208 \mathrm{mg} \mathrm{cm}^{-2}$ ) were studied at $160{ }^{\circ} \mathrm{C}$ (air and $\mathrm{H}_{2}$ flow rate 250 and $100 \mathrm{~cm}^{3} \mathrm{~min}^{-1}$ ), while maintaining atmospheric conditions. As shown in Figure 3, they observed that current density values increased with decrease in Pt loading of cathode electrode and found that the electrode having $0.712 \mathrm{mg} \mathrm{cm}^{-2} \mathrm{Pt}$ loading showed the highest current density values due to the highest ECSA. Therefore, low Pt loading electrode means thin $\mathrm{CL}$, when most of the catalyst is concentrated in the interface between $\mathrm{CL}$ and electrolyte membrane, resulting in higher Pt utilization.

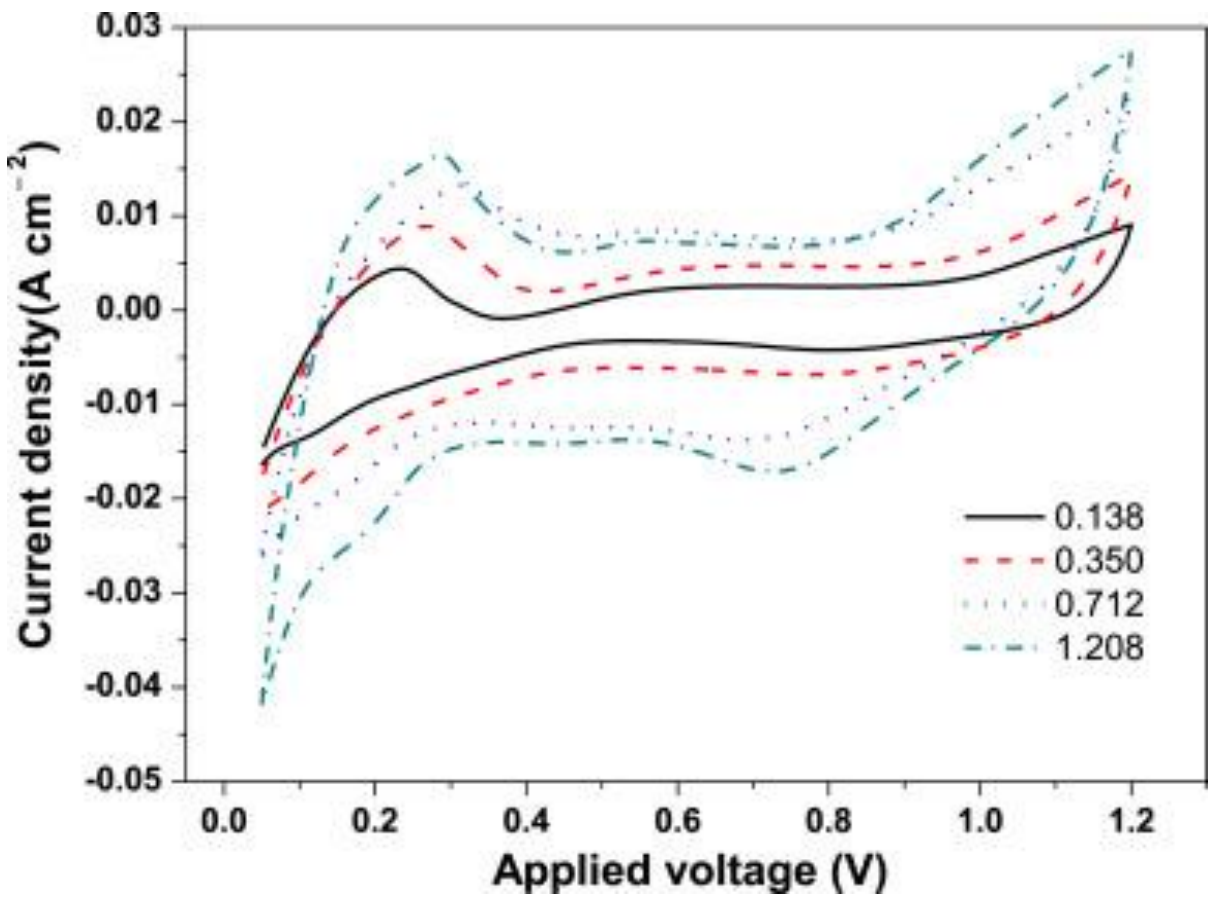

Figure 3. CV profiles of GDEs with different catalyst loadings. Reproduced from [34] with permission from Elsevier

Nabil et al. [35] electrochemically characterized the novel niobium carbide/carbon nano tubular porous structure $(\mathrm{NbC})$ as the catalyst support for PEMFC electrodes. Supports were prepared by electrospinning and functionalized with Pt nano particles. The ORR activity and catalyst stability 
showed less ECSA for Pt/NbC/C $\left(43 \mathrm{~m}^{2} \mathrm{~g}^{-1}\right)$ than for geometrically calculated surface area $\left(90 \mathrm{~m}^{2} \mathrm{~g}^{-1}\right)$. The less conductive $\mathrm{Nb}_{2} \mathrm{O}_{5}$ was stated as a reason for lower PtUt. Also, $31 \%$ retention in ECSA was observed for Pt/NbC/C after 10,000 cycles when compared with commercial Pt/C (only $5 \%$ retention). The greater stability is attributed to the corrosion resistance of one dimensional $\mathrm{NbC}$ nanostructures.

The same group [36] using the same technique synthesized nanotubes with suitable properties as the catalyst support for PEMFC cathode. $3 \mathrm{~mm}$ Pt particles were deposited on $\mathrm{NbC}$ nanotubes. From electrochemical characterization, they observed less ECSA $\left(43 \mathrm{~m}^{2} \mathrm{~g}^{-1}\right)$ for $30 \% \mathrm{Pt} / \mathrm{NbC}$ than for $50 \%$ $\mathrm{Pt} / \mathrm{C}$. Also, better stability was found for the novel support than commercial $50 \% \mathrm{Pt} / \mathrm{C}$, when ECSA of both catalysts were equal. Summarized results for the above category are given in Table 2.

Table 2. Reducing Pt loading and decreasing particle size (PEMFC cathode)

\begin{tabular}{lcccc}
\hline Method / Technique / Support & Pt loading, $\mathrm{mg} \mathrm{cm}^{-2}$ & $\mathrm{ECSA}, \mathrm{m}^{2} \mathrm{~g}^{-1}$ & PtUt, \% & Reference \\
\hline Electrospray & 0.012 & -- & & {$[29]$} \\
\hline Carbon microporous layer (CMPL) & 0.01 & -- & & {$[31]$} \\
\hline Electrospinning/Electrospray (E/E) & 0.022 & 93.9 & & {$[32]$} \\
\hline Porous PtNT & 40 & 23.9 & 127 & {$[33]$} \\
\hline Ultra sonic spray coating technique & 0.713 & 28.38 & -- & {$[34]$} \\
\hline Electrospinning (Pt/Nb/C) & 0.2 & 43 & - & {$[35]$} \\
\hline Electrospinning (Pt/Nb/C) & $30 \% \mathrm{Pt}$ & 43 & - & {$[36]$} \\
\hline
\end{tabular}

Improving Pt dispersion

Dispersion of Pt on different carbon supports has been explored using various methods such as impregnation-reduction, ion exchange (IE), micro emulsion-based synthesis, etc. The supports used may include Vulcan, multiwalled carbon nanotubes (MWCNT), Vulcan XC-72R, carbon aerogel (CA), BP2000, activated carbon, carbon cryogel and others. The objective of dispersion is to reduce average Pt particle size and hence, to increase the catalytic surface area [37].

Bayrakceken et al. [38] deposited Pt nanoparticles of size 1-2 nm uniformly distributed on carbon supports (Pt/VXR, Pt/MWCNT, Pt/BP2000) using super critical carbon dioxide deposition technique (Figure 4).

a

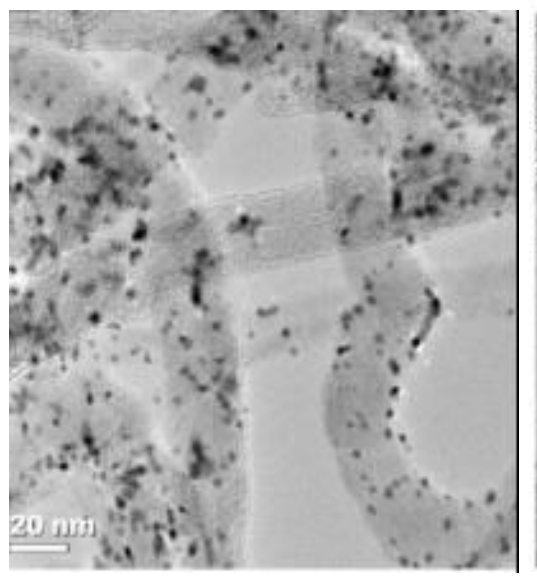

b

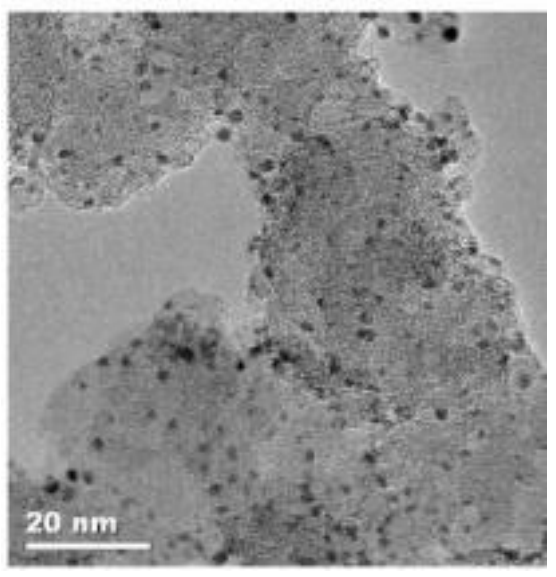

C

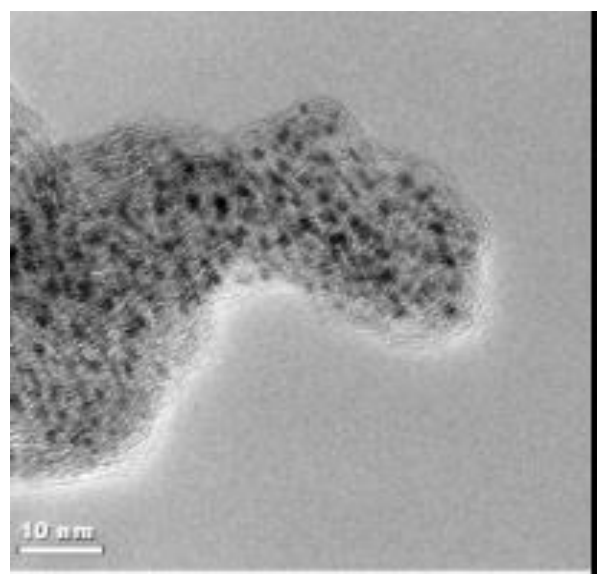

Figure 4. HRTEM images of Pt particles on different carbon supports (a) Pt/VXR (b) Pt/MWCNT and (c) Pt/BP2000. Reproduced from [38] with permission from Elsevier

They achieved nearly three times higher ECSA ( $173 \mathrm{~m}^{2} \mathrm{~g}^{-1}$ for Pt/VXR) with the reduced Pt loading when compared to a commercial catalyst $\left(57 \mathrm{~m}^{2} \mathrm{~g}^{-1}\right)$. The authors assumed that even for smaller Pt particles, the hydrophobic nature of carbon support makes Pt particles inaccessible for electrolytes. 
Here, the highest PtUt of $93 \%$ was observed for Pt/MWCNT with ECSA of $130 \mathrm{~m}^{2} \mathrm{~g}^{-1}$. The observed differences were due to variation in structure of carbon supports.

Fang et al. [39] deposited PtNTs on Vulcan XC-72 (VC) carbon black (CB) by employing the homogeneous deposition technique with ethylene glycol (EG) (reducing agent) using polyol process (HD-EG). They found higher ECSA of $78 \mathrm{~m}^{2} \mathrm{~g}^{-1}$ with high Pt utilization of $78 \%$ when compared with the microwave (EG-MW) assisted polyol approach or conventional sodium borohydride $\left(\mathrm{NaBH}_{4}\right)$ reduction process. This highest Pt utilization ( 60 wt\% on VC by HD-EG) was attributed to the relatively small PtNP with improved particle dispersion creating more active sites for the anticipated reactions.

Mroz et al. [40] used the pulse laser deposition (PLD) method for depositing catalyst films directly on Nafion ${ }^{\circledR}$ membranes and GDL and achieved accurately controlled low catalyst loadings with greater uniformity. Under various pressure ranges, electrodes were prepared and studied by varying thickness of the catalyst film between 0.09 and $3.47 \mathrm{~nm}$, in proportion to the laser pulses between 75 and 3000 . At low cell voltage, the results revealed higher current densities and less transport resistance of reagents when compared to cells with Pt catalyst placed on the Nafion ${ }^{\circledR}$ membrane. In the case of high cell voltages, low currents were generated due to less active surface area of Pt available for reactions. The authors stated that the efficiency can be further increased by growing the contact area between electrolyte and catalyst and also by enhancing the reaction zone to advance the passage of reagents.

Rost et al. [41] deposited Pt particles on carbon nanofibers (CNF) by employing the pulse plating technique (PPT). They observed 3.1 times higher ECSA of $148.6 \mathrm{~cm}^{2} \mathrm{mg}^{-1}$ with CNF functionalization at $120 \mathrm{~W}$ for $10 \mathrm{~min}$. The creation of the functional groups on fibrous surface of the nanoparticles and graphene $(\mathrm{Gr})$ is stated as the reason for smaller and homogenous dispersion of catalyst.

Huang et al. [42] used the impregnation method to synthesize highly dispersed Pt catalyst with addition of centyltrimethylammonium bromide (CTAB) as dispersant at $300{ }^{\circ} \mathrm{C}$. They prepared $\mathrm{CL}$ samples with different Pt loadings and observed higher ECSA and high PtUt for the catalyst sample with $4.12 \mathrm{mg} \mathrm{cm}^{-2}$ dispersant concentration. The improved results were attributed to lypophilic alkyl and hydrophilic amine groups of CTAB.

Lv et al. [43] synthesized the novel carbon mixed carbide-based catalyst support $(\mathrm{SiC} / \mathrm{C})$ to improve electrochemical performance and catalytic activity of PEMFC cathode. They deposited Pt catalyst on nano $\mathrm{SiC} / \mathrm{C}$ particles and observed homogenous dispersion of Pt particles on nano-SiC particles with evidently increased ECSA $\left(48 \mathrm{~m}^{2} \mathrm{~g}^{-1}\right)$ for Pt/SiC/C when compared to Pt/SiC $\left(13 \mathrm{~m}^{2} \mathrm{~g}^{-1}\right)$. The addition of carbon to $\mathrm{Pt} / \mathrm{SiC}$ and uniform dispersion of $\mathrm{Pt}$ nano particles on the novel support were attributed to the increased PtUt in ORR activity of PEMFC electrode. Summarized results for the above category are given in Table 3.

Table 3. Improving Pt dispersion (PEMFC cathode)

\begin{tabular}{cccccc}
\hline Dispersion echnique dispersant & Catalyst support & Pt loading & $\mathrm{ECSA}, \mathrm{m}^{2} \mathrm{~g}^{-1}$ & PtUt, \% & Ref. \\
\hline & Pt/VXR & $9.0 \mathrm{wt} \%$ & 173 & 74 & \\
& $\mathrm{Pt} / \mathrm{CNT}$ & $9.9 \mathrm{wt} \%$ & 130 & 93 & {$[38]$} \\
& Pt/BP2000 & $47.5 \mathrm{wt} \%$ & 102 & 36 & \\
\hline $\mathrm{HG}-\mathrm{CD}$ & $\mathrm{CB}$ & $0.2 \mathrm{mg} \mathrm{cm}^{-2}$ & 78 & 78 & {$[39]$} \\
\hline $\mathrm{PLD}$ & $\mathrm{CB}$ & $1.24 \mu \mathrm{g} \mathrm{cm}^{-2}$ & - & - & {$[40]$} \\
\hline $\mathrm{PPT}$ & $\mathrm{Pt} / \mathrm{CNF}$ & $1 \mathrm{mg} \mathrm{cm}{ }^{-2}$ & 148.6 & - & {$[41]$} \\
\hline $\mathrm{CTAB}$ & $\mathrm{CTAB}:$ & $0.096 \mathrm{mg} \mathrm{cm}^{-2}$ & 65.97 & 63.53 & {$[42]$} \\
\hline EG reduction method & $\mathrm{Pt} / \mathrm{SiC} / \mathrm{C}$ & $20 \%$ & 48 & & {$[43]$} \\
\hline
\end{tabular}




\section{Structural modification of catalyst layer}

Catalyst layer needs to be designed in order to ensure effective movement of electrons, protons, reactant gas, and water through a porous medium. Structural modification of CL aims to improve mass transport, decrease interfacial resistance between catalyst layer and gas diffusion layer, enhance catalyst utilization, and reduce Pt loading [44].

Su et al. [45] replaced the conventional double catalyst layer (DCL) with a novel double carbon layer (NDCL) cathode with high Pt content for inner layer and low Pt content for outer layer. Five cathodes (NDCL-1 to NDCL-5) with different Pt distribution ratio of inner and outer layers were prepared (Table 4).

From CV (Figure 5), better ECSA for the novel DCL than single catalyst layered (SCL) and conventional DCL catalysts can be observed. The highest ECSA of $81.4 \mathrm{~m}^{2} \mathrm{~g}^{-1}$ was recorded for NDCL2 having the same inner and outer layer thicknesses, which was attributed to the reduced mass transport resistance. Further, the reduced catalyst and Nafion ${ }^{\circledR}$ content in outer layer was proved beneficial for ORR and water removal.

Table 4. Five DCL cathodes with different inner and outer Pt distribution ratios [45]

\begin{tabular}{ccccccc}
\hline Novel double catalyst layer cathode & NDCL-1 & NDCL-2 & NDCL-3 & NDCL-4 & NDCL-5 \\
\hline Pt distribution (inner : outer) & $9: 1$ & $8: 2$ & $7: 3$ & $6: 4$ & $5: 5$ \\
\hline$L_{\text {out }} / L_{\text {in }}$ (estimated value) & a & 0.44 & 1 & 1.71 & 2.78 & 3.91 \\
\hline
\end{tabular}

${ }^{a} L_{\text {out }}$ : outer catalyst layer thickness, $L_{\text {in }}$ : inner catalyst layer thickness.

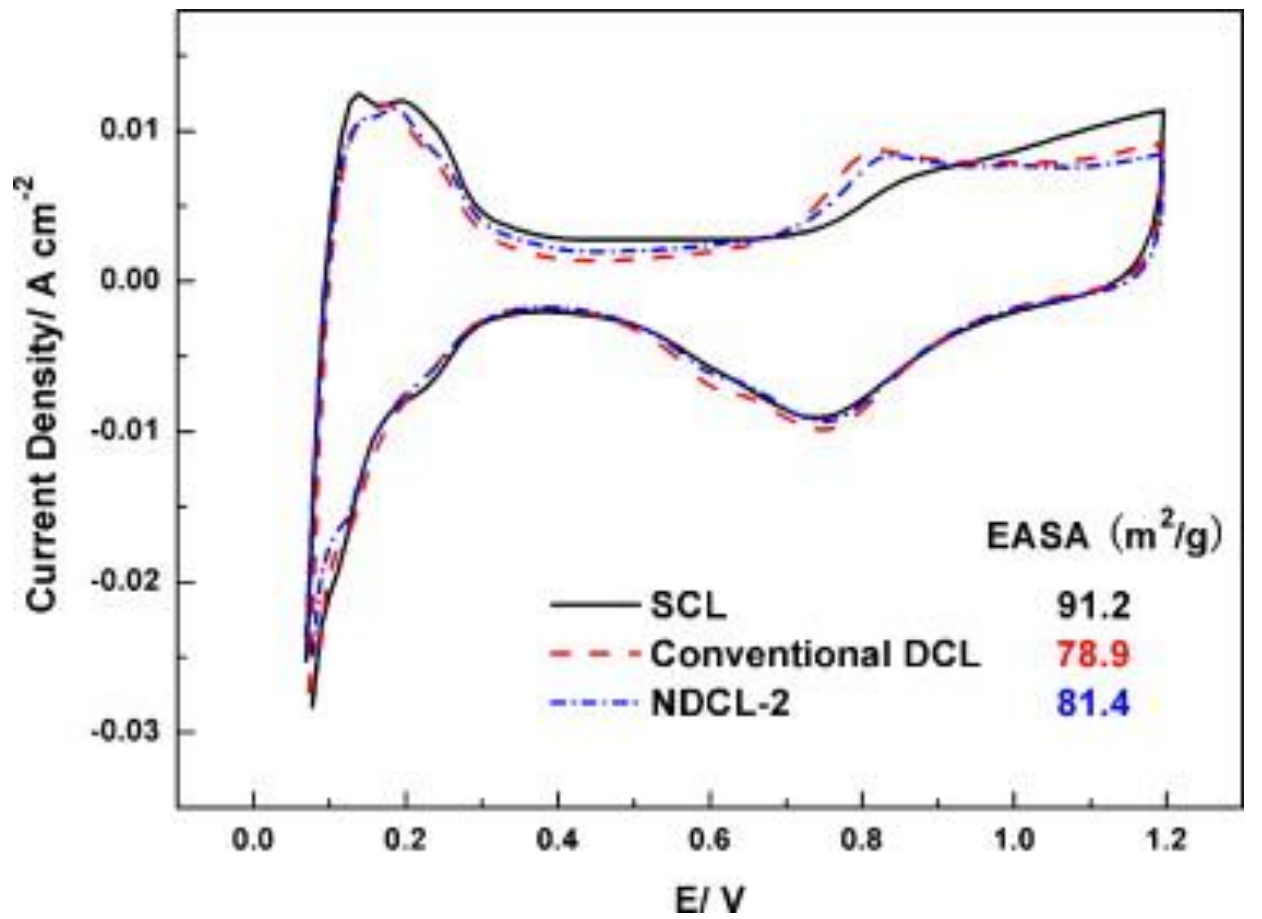

Figure 5. CVs for MEA with single, conventional double and novel double catalyst layered cathode structures. Reproduced from [45] with permission from Elsevier (ESCA is marked as EASA on the graph

Qiu et al. [46] developed a novel cathode structure (NCS) having double catalyst layer with reduced Pt loadings of $0.23 \mathrm{mg} \mathrm{cm}^{-2}$ and $0.11 \mathrm{mg} \mathrm{cm}^{-2}$ for inner and outer $\mathrm{CL}$, respectively (Figure 6). The NCS was provided with hydrophobic and hydrophilic regions. It was observed that rich small pores of the outer layer provided efficient electrochemical active surface with the reduced GDL interfacial resistance, improving thus mass transfer. The compact structure of the inner layer 
provided more active catalyst sites, resulting in improved migration of protons towards the membrane. The results showed $50 \%$ Pt utilization for the developed NCS which was $28 \%$ higher than that of traditional catalyst structure (TCS).

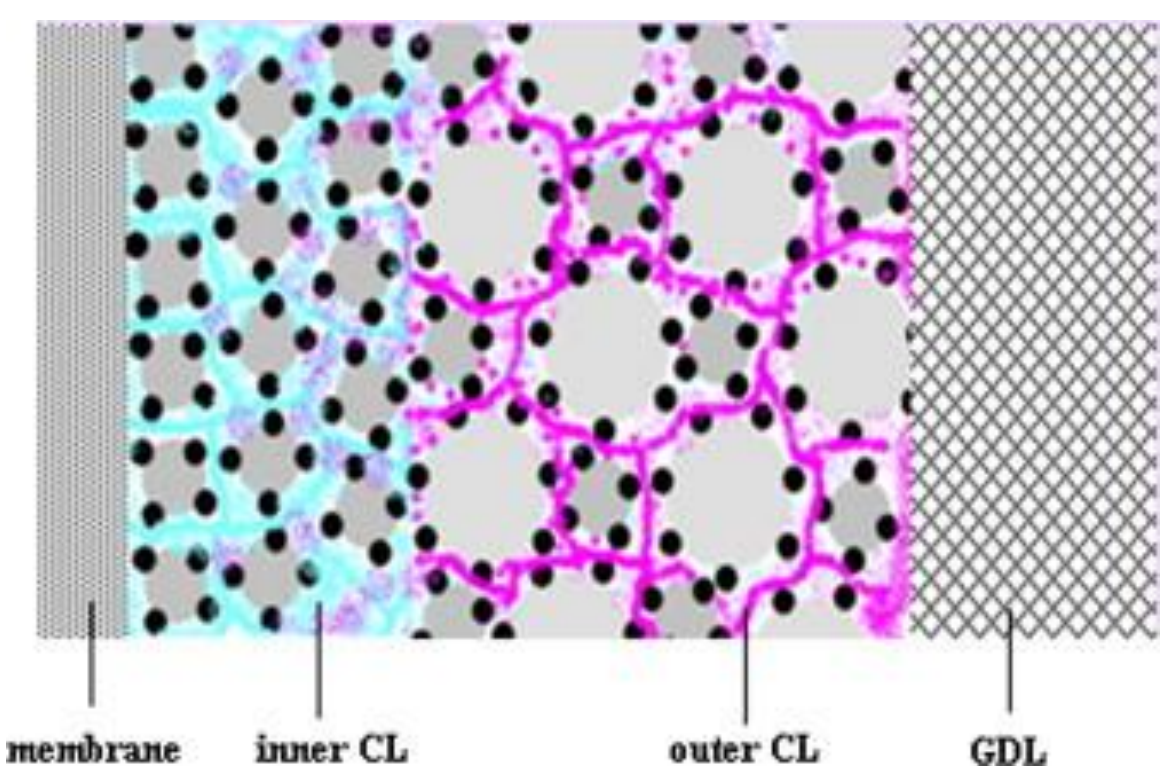

Figure 6. Schematic of novel cathode structure (NCS). Reproduced from [46] with permission from Elsevier

Avcioglu et al. [47] made an attempt to explain the significance of $\mathrm{CL}$ in water management since $\mathrm{CL}$ impacts water balance, while water flooding leads to mass transfer limitation at high current densities. To enhance durability performance and to ensure efficient thermal and water management in the components of PEMFC, the authors constructed a mesoporous hydrophobic channeled catalyst layer by addition of poly(tetraflouroethylene) (PTFE) nanoparticles and employing a two-step catalyst preparation method. By electrochemical characterization of three different types of catalyst viz., Pt/C, Pt/C-Nafion ${ }^{\circledR}$, Pt/C-Nafion ${ }^{\circledR} / \mathrm{PTFE}$, it was found that addition of PTFE to the catalyst diminished Pt agglomeration, but reduced ECSA and PtUt of Pt/C-Nafion ${ }^{\circledR} / \mathrm{PTFE}$. It was concluded that higher ECSA $\left(77 \mathrm{~m}^{2} \mathrm{~g}^{-1}\right)$ was observed for Pt/C catalyst because of increased total catalyst surface area. The ECSA $\left(70 \mathrm{~m}^{2} \mathrm{~g}^{-1}\right)$ of Pt catalyst with Nafion ${ }^{\circledR}$ (Pt/Nafion ${ }^{\circledR}$ ) was slightly reduced, but PtUt was improved due to formation of Pt agglomerates by Nafion ${ }^{\circledR}$ addition. The ECSA of Pt/Nafion ${ }^{\circledR} /$ PTFE, however, was only $45 \mathrm{~m}^{2} \mathrm{~g}^{-1}$ and PtUt was $56 \%$ with enhanced diffusion process in the catalyst layer. Disruption of TPB, active sites blockage and increased average pore diameter were stated as the consequences of PTFE addition.

In order to overcome kinetic loss occurring at low Pt loading, Breitwieser et al. [48] employed a direct membrane deposition technique (DMD) in MEA fabrication process, wherein the conventionally free-standing membrane was replaced by two 8-15 $\mu \mathrm{m}$ thin ionomer layers with low Pt loading of $0.102 \mathrm{mg} \mathrm{cm}^{-2}$ on anode and $0.029 \mathrm{mg} \mathrm{cm}^{-2}$ on cathode, respectively. At $300 \mathrm{kPa}_{\mathrm{abs}}$ of total pressure and under oxygen atmosphere, the DMD fuel cell yielded a maximum power density of $2.56 \mathrm{~W} \mathrm{~cm}^{-2}$ with very high PtUt of about $88 \mathrm{~kW} \mathrm{~g}^{-1}$. This value was 2.3 fold higher than that of a commercial Nafion N-211 membrane reference fuel cell. The high PtUt efficiency was attributed to the novel DMD fabrication technique, which favored lower ionic resistance and improved power density in the high current density range.

To reduce Pt loading, Kaplan et al. [49] developed Pt alloys and core-shell structures. They synthesized two carbon supported Pt-surface enriched nano sized (Pt-SENS) catalysts and performed characteristic studies with a partial Pt shell and low-cost ruthenium (Ru) and iridium (Ir) 
metal cores. Instead Pt loading of $48 \mathrm{mg} \mathrm{cm}^{-2}$ for commercial Pt catalyst, they used Pt loading of 14 $\mathrm{mg} \mathrm{cm}{ }^{-2}$ for Pt/Ir/XC72 and $19.5 \mathrm{mg} \mathrm{cm}^{-2}$ for Pt/Ru/XC72 prepared electrodes. ECSA of $29 \mathrm{~m}^{2} \mathrm{~g}^{-1}$ was obtained for Pt/Ru/XC72 catalyst using CO-stripping method, while $26 \mathrm{~m}^{2} \mathrm{~g}^{-1}$ for Pt/Ir/XC72 and 48 $\mathrm{m}^{2} \mathrm{~g}^{-1}$ for $50 \%$ wt Pt/C were obtained by HUPD method. It was concluded that Pt-surface-enriched structure increased availability of Pt particles for the catalytic reactions.

Chen et al. [50] designed a new gradient cathode with appropriate $\mathrm{Pt} / \mathrm{C}$ ratio gradient direction (70 wt\% inner side and 40 wt\% outer sides) and Nafion ${ }^{\circledR}$ gradient span (33 wt\% inner side and $23 \mathrm{wt} \%$ outer sides). This improved both Pt utilization and mass transfer, thus significantly improving the performance. Especially under low humidity, the performance of appropriate gradient MEA was $135.7 \%$ higher than the MEA with SCL cathode at $20 \%$ relative humidity. It also provided better water management, improved proton conductivity in cathode, and showed lower ohmic resistance and charge transfer resistance. Summarized results for the above category are given in Table 5.

Table 5. Structural modification of catalyst layer (PEMFC Cathode).

\begin{tabular}{|c|c|c|c|c|}
\hline Novel Cathode Structure & Pt Loading & ECSA, $m^{2} g^{-1}$ & PtUt, \% & References \\
\hline NDCL & $0.2 \mathrm{mg} \mathrm{cm}^{-2}$ & 81.4 & -- & [45] \\
\hline NCS & $0.4 \mathrm{mg} \mathrm{cm}^{-2}$ & 35.42 & 50.56 & [46] \\
\hline $\mathrm{Pt} / \mathrm{C}$ & $21 \mathrm{wt} \%$ & 77 & 75 & \multirow{3}{*}{ [47] } \\
\hline Pt/C-Nafion ${ }^{\circledR}$ & $13 w t \%$ & 70 & 99 & \\
\hline Pt/C-PTFE & $8 w t \%$ & 45 & 56 & \\
\hline DMD & $29 \mu \mathrm{g} \mathrm{cm}^{-2}$ & & $88 \mathrm{~kW} \mathrm{~g}{ }^{-1}$ & [48] \\
\hline $\mathrm{Pt} / \mathrm{Ru} / \mathrm{XC72}$ & $19.5 \mu \mathrm{g} \mathrm{cm}^{-2}$ & 29 & -- & \multirow{2}{*}{ [49] } \\
\hline $\mathrm{Pt} / \mathrm{Ir} / \mathrm{XC72}$ & $14 \mu \mathrm{g} \mathrm{cm}^{-2}$ & 26 & -- & \\
\hline $\mathrm{Pt} / \mathrm{C}$ \&Nafion ${ }^{\circledR}$ ratio & $200 \mu \mathrm{g} \mathrm{cm}^{-2}$ & 8.4 & -- & [50] \\
\hline
\end{tabular}

\section{Optimization of catalyst parameters}

High Pt utilization can be achieved by optimizing various catalyst layer parameters such as Nafion ${ }^{\circledR}$ content, Pt loading, Teflon content, catalyst layer and carbon support thicknesses, etc. [51].

Cheng et al. [52] investigated the effect of Nafion ${ }^{\circledR}$ and PTFE on PtUt for two catalyst layers: a) ETEK electrode/GDE prepared using immersion method where Pt is impregnated with $\mathrm{Nafion}^{\circledR}$ and b) thin film catalyst layer (TFCL) prepared by blending Nafion ${ }^{\circledR}$ and Pt catalyst. PtUt of $77.8 \%$ and 45.4 $\%$ were observed for the first and the second catalyst layer, respectively. It was concluded that while the catalyst particles are provided with sufficient passage ways for the transfer of protons in the first case, the thin film catalyst layer experienced lack of conduction because of the blockage of passage ways by the Nafion ${ }^{\circledR}$ solid.

Antolini et al. [53] investigated the effect of Nafion ${ }^{\circledR}$ loading on ORR at PEMFC electrode. They observed that the electrode exhibited poor electrolytic conductivity at low Nafion ${ }^{\circledR}$ loading and that ECSA increased with increasing content of Nafion ${ }^{\circledR}$ (Figure 7). The introduction of Nafion ${ }^{\circledR}$ is stated to improve the active surface area, resulting in better transport of protons through the electrolyte.

Sasikumar et al. [54] investigated the dependence of Nafion ${ }^{\circledR}$ content on Pt loading. Electrodes were prepared with different Pt loadings $\left(0.5,0.25,0.1 \mathrm{mg} \mathrm{cm}{ }^{-2}\right)$ and different Nafion ${ }^{\circledR}$ ionomer contents (20, 30, 40, 50, 60 wt\%). The highest PtUt (52 \%) was obtained at 40 wt\% Nafion ${ }^{\circledR}$ content for Pt content of $0.25 \mathrm{mg} \mathrm{cm}^{-2}$. The authors concluded that Nafion ${ }^{\circledR}$ content must be determined by Pt loading and the fabrication technique used. The electrode performance was found to improve with enhancement of Nafion ${ }^{\circledR}$ content up to $40 \%$, but further increase in Nafion ${ }^{\circledR}$ content reduced the performance. The reasons attributed to this effect are blockage of Pt sites, decreased gas 
permeability and augmented mass transport polarization. The increased distance for gas permeation, diffusion and migration are stated as reasons for transport limitation.

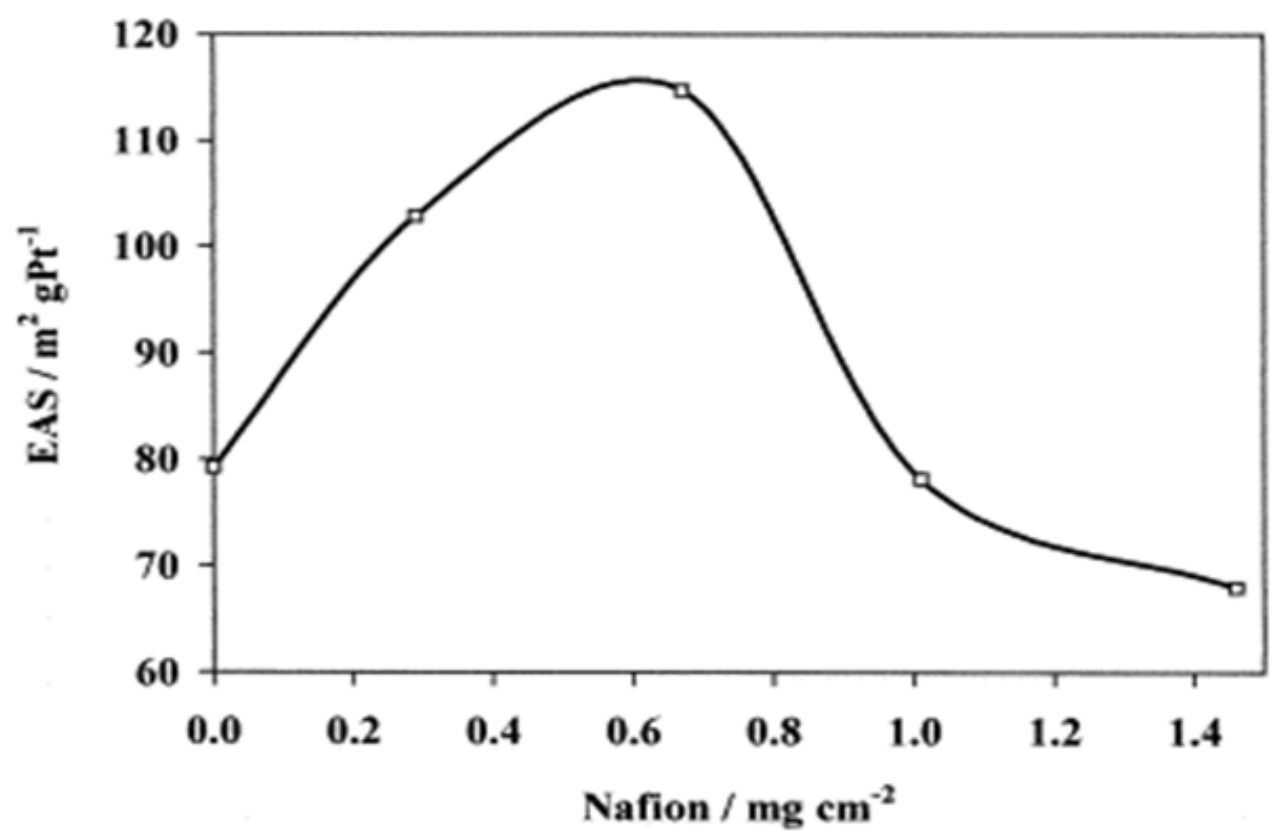

Figure 7. ECSA (marked as ESA on the graph) variation with Nafion ${ }^{\circledast}$ loading in the $C L$ ( 20 wt\% PTFE/C on DL, $0.2 \mathrm{mg} \mathrm{cm}^{-2}$ of Pt in CL). Reproduced from [53] with permission from Elsevier

Jiang et al. [55] studied the effect of thickness of carbon supported Pt catalyst layer in ORR using a thin film rotating disc electrode. Various catalyst layer thicknesses $(0.25,0.5,1.0,2.0,4.0,8.0 \mathrm{~mm})$ were examined. The highest PtUt (77.9\%) was observed for $8.0 \mathrm{~mm}$ film. It was concluded that ECSA tends to increase with increasing thickness of the catalyst layer, showing more activity towards ORR accordingly.

Bayrakceken et al. [56] used super critical $\mathrm{CO}_{2}$ deposition to prepare Vulcan supported Pt catalyst (Pt/Vulcan) and studied the effect of thermal reduction. Samples with Pt loading of $9 \%, 15 \%, 35 \%$ were produced and ECSA were investigated using CV. The order of ECSA was found as follows: Pt/Vulcan $35 \%<$ Pt/Vulcan $15 \%<$ Pt/Vulcan $9 \%$. Although ECSA for Pt/Vulcan $15 \%$ was found higher than for Pt/Vulcan $35 \%$, the PtUt was lower. This difference is, however, quite small (58 \% vs. $62 \%$ ) and is not considered significant related to the uncertainty in both the calculated and the measured average Pt particle sizes. The difference in ECSA between Pt/Vulcan $15 \%$ and $35 \%$ catalysts is attributed to the differences in the Pt particle sizes, since ECSA Pt values differ by a factor of approximately 1.5 .

Using plasma dc-magnetron sputtering technique, Khan et al. [57] studied the conical nanopillar structured Pt catalyst sputtered on the cathode with argon pressures of $0.05,0.1,0.5 \mathrm{mbar}$ and at $\mathrm{Pt}$ loading range of $0.05-0.2 \mathrm{mg} \mathrm{cm}$. They observed high ECSA for the catalyst nanopillar deposited at $0.5 \mathrm{mbar}$ at low Pt loading of $0.05 \mathrm{mg} \mathrm{cm}^{-2}$. It was concluded that the deposition of uniform conical nanopillars on the electrode at high pressure improved catalytic activity and led to higher PtUt.

Slavcheva et al. [58] studied the effect of sputtering parameters (film thickness, argon pressure, dcsputtering power) on thin films deposited by dc-sputtering technique. At low sputtering power (120$130 \mathrm{~nm}$ thick Pt films, 6 mTorr argon pressure, $100 \mathrm{~W}$ dc power), they found a stable and crystalline catalyst film with thickness between 120-130 nm, with large ECSA and PtUt. It was concluded that ECSA increased with increase of film thickness and improved the electrochemical activity towards ORR. 
Wang et al. [59] studied the influence of PTFE on electro spun/electro sprayed (E/E) MEA. They introduced only $1 \mathrm{wt} \%$ PTFE to the process which resulted in PtUt of $0.076 \mathrm{~g} \mathrm{~kW}^{-1}$ at only $0.094 \mathrm{mg} \mathrm{cm}^{-2} \mathrm{Pt}$ loading. The improvement was attributed to enhanced hydrophobicity of the nanofibers which increases mass transfer and overall performance.

Speder et al. [60] studied the effect of Pt/carbon ratio on degradation of PEMFC catalyst. They used a colloidal synthesis approach for Pt/Vulcan and Pt/KetjenBlack catalysts using accelerated stress test (AST) in half cells. It was concluded that the loss in ECSA due to AST treatment depends on carbon support and Pt loading.

Zhao et al. [61] investigated the impact of pore size of FDU-15 (two-dimensional hexagonal ordered mesoporous carbon (OMC)) supported Pt catalyst by adopting a soft-template method. Samples with four different pore sizes ranging from $4.0 \mathrm{~nm}$ to $8.1 \mathrm{~nm}$ were prepared by the addition of pore expanding agents. By impregnation method, Pt catalysts were prepared using FDU-15 samples as catalyst supports and reducing agent, EG. CV and linear sweep voltammetry (LSV) measurements illustrated that catalyst with a pore size of $6.5 \mathrm{~nm}$ showed the highest ECSA $\left(70.2 \mathrm{~m}^{2}\right.$ $\left.\mathrm{g}^{-1}\right)$. It was also observed that Pt particle size is reduced with increase in pore size up to $6.5 \mathrm{~nm}$ and remained unchanged with further increase in pore size.

Kim et al. [62] examined the effect of diffusing solvents with varying main chain mobility of Nafion ${ }^{\circledR}$ to demonstrate large influence on Nafion ${ }^{\circledR}$ agglomerates, morphology and other properties such as proton conductivity and water uptake. The MEA synthesized from the dimethyl sulfoxide based isopropyl alcohol (IPA) and N-methyl-2-pyrrolidone (NMP)-based catalyst inks presented ECSA of 40.9, 43.0 and $52.5 \mathrm{~m}^{2} \mathrm{~g}^{-1}$, respectively. The introduction of diffusing solvents resulted in better diffusion of Nafion ${ }^{\circledR}$ into Pt/C aggregates, bringing more Pt particles in contact with Nafion ${ }^{\circledR}$ thereby increasing the catalytic activity at reduced current density.

Ruengkit et al. [63] investigated the influence of GDL properties (type of material (carbon paper (CP), carbon cloth (CC)), thickness, PTFE content and presence of micro porous layer (MPL)) on ECSA of Pt electrodeposited layer and fuel cell performance. Pt catalyst was electrodeposited by dc current onto GDL, with CC and CP of different thicknesses and hydrophobicity, and with and without presence of MPL. Despite their morphological differences, relatively similar ECSA $\left(\sim 120 \mathrm{~m}^{2} \mathrm{~g}^{-1} \mathrm{Pt}\right)$ were obtained, while better performance for $\mathrm{CC}$ at higher current densities is due to its lower resistance and higher porosity. Pt deposited on a very thin GDL $(90 \mu \mathrm{m})$ or GDL having high PTFE content $(\geq 30 \%)$ or containing MPL, consist of non-uniform particles distributed unevenly on the GDL surfaces, resulting in low ECSA ( $\leq 120 \mathrm{~m}^{2} \mathrm{~g}^{-1} \mathrm{Pt}$ ) and FC performances (is $210 \mathrm{~mA} \mathrm{~cm}{ }^{-2}$ ). Pt electrodeposition on the CC having low PTFE content ( $10 \%$ ) produced small and uniform Pt particles distributed evenly throughout the GDL surfaces resulting in highest ECSA (193 $\left.\mathrm{m}^{2} \mathrm{~g}^{-1} \mathrm{Pt}\right)$. The same phenomenon was also observed for the two-layered GDL, which is attributed to the absence of the hydrophobic sublayer in the posttreatment of the GDL. It was concluded that selection of GDL as the fuel cell electrode is crucial when Pt catalyst is prepared by electrodeposition.

Egetenmeyer et al. [64] investigated electrodeposition of cathode catalyst layer using the plasma process. At different catalyst loadings and plasma durations, nanostructured $\mathrm{Pt}$ and $\mathrm{Pt}_{3} \mathrm{Co}$ cathodes were prepared with varying quantity of ionomer and its distribution in the cathode catalyst layer $(\mathrm{CCL})$. There was an increase of ECSA in comparison with the untreated substrate. ECSA increased with increase in the plasma treatment duration up to $23.1 \mathrm{~m}^{2} \mathrm{~g}^{-1}$ (highest) after $15 \mathrm{~min}$ plasma treatment, which is indicative of the deposition of smaller Pt particles on the electrode. Summarized results for the above category are given in Table 6. 
Table 6. Optimization of catalyst parameters (PEMFC cathode)

\begin{tabular}{|c|c|c|c|c|}
\hline Parameter/Variable/Method & Pt Loading, $\mathrm{mg} \mathrm{cm}^{-2}$ & ECSA, $m^{2} g^{-1}$ & PtUt, \% & Ref. \\
\hline TFCL & 0 & 63.6 & 45.4 & [5 \\
\hline GDE & 0.4 & -- & 77.8 & {$[52]$} \\
\hline Nafion ${ }^{\circledR}$ loading & 0.2 & 115 & -- & [53] \\
\hline Optimum Nafion ${ }^{\circledR}$ content & 0.25 & $648 \mathrm{~cm}^{2}$ & 52 & [54] \\
\hline Thickness of $\mathrm{CL}$ & 0.256 & 91.1 & 77.9 & [55] \\
\hline Thermal reduction $\left(\mathrm{ScCO}_{2}\right)$ & 0.028 & 173 & 74 & [56] \\
\hline dc-sputtering parameters & 0.05 & 106.10 & -- & [57] \\
\hline dc-magnetron sputtering parameters & & $47.09 \mathrm{~cm}^{2}$ & 93.62 & [58] \\
\hline Effect of PTFE on electro spun /electro sprayed MEA & 0.094 & 81 & & [59] \\
\hline Platinum loading & 14 & 126.5 & - & [60] \\
\hline Pore size on OMC/FDC-15 & 2 & 70.2 & - & [61] \\
\hline Solvent effect (NMP) & 0.2 & 52.2 & - & [62] \\
\hline Effect of GDL thickness & 0.25 & 193 & - & [63] \\
\hline Plasma process & 0.3 & 23.1 & - & [64] \\
\hline
\end{tabular}

\section{Improving the performance of Pt support materials}

The selection of appropriate support materials plays a key role in enhancing the overall performance of PEMFC and DMFC. Characteristics of good support material include presence of surface functional groups that promote catalyst-support interaction, mesoporous structure which improves triple phase boundary (TPB), good electrical conductivity and electrochemical stability, high surface area and corrosion resistance. Typically, conductive and porous membranes are known to possess above mentioned features and are therefore preferred as support materials for Pt catalyst [44].

Existing research reveals that use of carbon-based support with various structural and morphological properties improved stability and electrocatalytic activity of catalyst. In addition, mass transfer and electronic conductivity in $\mathrm{CL}$ are also found to be enhanced at carbon supports. Some of the novel carbon-based support materials investigated so far are carbon nanofibers (CNF), ordered mesoporous carbons, carbon aerogels, carbon nanohorns, carbon nanocoils and carbon nanotubes (CNT) [44].

In this connection, Zhao et al. [65] demonstrated that nearly $100 \%$ of Pt can be exposed to catalytic activity by using gold nanoparticles as Pt catalyst support (AuPt). ECSA measurements were carried out on Vulcan XC-72 CB samples by varying Pt and Au ratio. Prominent enhancement of ECSA and $\mathrm{Pt}$ utilization was observed when $\mathrm{Pt} / \mathrm{Au}$ ratio becomes lower than 0.2. Further decrease of $\mathrm{Pt} / \mathrm{Au}$ ratio to 0.05 or less, makes ECSA and PtUt to increase up to $100 \%$. This approach ensured uniform dispersion of Pt particles and prevented pocketing in the micropores of supported material, making thus Pt particles efficient for ORR.

Kongkanand et al. [66] and Orfanidi et al. [67] elucidated use of carbon nanotubes (SWCNT) and (MWCNT) as Pt catalyst supports. Pt particles supported on SWCNT showed lower ECSA $\left(17.8 \mathrm{~m}^{2} \mathrm{~g}^{-1}\right)$ than the commercial carbon support $\left(33.5 \mathrm{~m}^{2} \mathrm{~g}^{-1}\right)$ with $10 \mathrm{mV}$ shift in the onset potential for ORR. They inferred that the commercially available Pt has better distribution of Pt nanoparticles than the one developed in the lab with SWCNT. Pt supported on MWCNT, however, showed improved ECSA of $78.4 \mathrm{~m}^{2} \mathrm{~g}^{-1}$ with $84 \%$ PtUt. Higher ECSA and better catalytic utilization were attributed to uniform dispersion and narrow particle size distribution ( 2.5 to $4 \mathrm{~nm}$ ).

Instead of using pure SWCNT, Zhu et al. [68] used a mixture of SWCNT and carbon nanofibers (CNF) at 1:3 (SF13) and 1:5 (SF15) ratios (Bucky paper) to prepare a novel catalyst. They observed reduced ECSA due to larger Pt particle size $(6 \mathrm{~nm})$ than of commercial catalyst support $(2 \mathrm{~nm})$. However, PtUt 
of $88 \%$ and $84 \%$ for SF13, SF15 were observed which was ascribed to availability of the catalyst particles at electrolytic and electronic pathways of the Bucky paper electrodes.

Kou et al. [69] investigated the properties of functionalized graphene sheets (FGS) as the cathode catalyst support, mostly because of higher conductivity, high surface area and low manufacturing cost with unique graphitized basal plane structure. Results revealed higher initial ECSA $\left(109 \mathrm{~m}^{2} \mathrm{~g}^{-1}\right)$ with improved stability when compared to the commercial catalyst (E-TEK, $75 \mathrm{~m}^{2} \mathrm{~g}^{-1}$ ). This was attributed to smaller Pt particle size of $2 \mathrm{~nm}$ and less extent of Pt nanoparticles agglomeration on FGS.

Salernitano et al. [70] used the controlled plasma improved chemical vapour deposition (CVD) technique to deposit Pt nanofibers on a support made from carbon nano fibers (CNF). Electrodes were prepared with different structures of CNF, by changing the orientation of graphene layers in relation to the fiber axis. This resulted in availability of large number of active sites for catalyst nanoparticles. Due to the controlled morphology grown of graphite paper, they found higher ECSA $\left(225 \mathrm{~m}^{2} \mathrm{~g}^{-1}\right)$ with improved PtUt at reduced Pt loading $\left(0.018 \mathrm{mg} \mathrm{cm}^{-2}\right)$.

Huang et al. [71] used conductive titanium oxide as Pt catalyst support and investigated $\mathrm{Pt} / \mathrm{TiO}_{2}$ durability and stability using in-house potential cyclic experiments. Although initially, the $\mathrm{Pt} / \mathrm{TiO}_{2}$ $\left(31.2 \mathrm{~m}^{2} \mathrm{~g}^{-1}\right)$ showed less ECSA than Pt/C $\left(56.4 \mathrm{~m}^{2} \mathrm{~g}^{-1}\right)$, it continued to remain stable even after 4000 cycles with minimum loss in ECSA. On the contrary, Pt/C showed no activity after 2000 potential cycles owing to Pt dissolution, carbon corrosion and Pt particles sintering. ECSA was calculated after 2500 cycles and observed larger ECSA for $\mathrm{Pt} / \mathrm{TiO}_{2}$ than $\mathrm{Pt} / \mathrm{C}$ catalyst.

Song et al. [72] developed the novel compound carbon supported Pt catalyst (Pt/CCS) by introducing ultra-fine porous carbon fibre (UPCF) powder to commercial Pt catalyst as a second carbon support. Partially supported Pt catalyst JM-40 catalyst with particle size $3.4 \mathrm{~nm}$ was combined with UPCF. Using CV measurements, it was observed that Pt/CCS-20 showed the highest PtUt with ECSA $71.9 \mathrm{~m}^{2} \mathrm{~g}^{-1}$.

Sanli et al. [73] used reduced graphene oxide ( $\mathrm{rGO}$ ) and carbon black hybrid material as Pt support and fabricated a novel cathode structure for PEMFC. Using electrospray technique, they synthesized platinum/reduced graphene oxide (Pt/r-GO) electrocatalyst and platinum/reduced graphene oxide/Vulcan XC-72, Pt/r-GO/VXC-72, hybrid electrocatalyst with 50 wt\% r-GO. Comparing the results with air-sprayed electrode, it was observed that Pt supported on the hybrid support (Pt/rGO/Vulcan XC-72) showed higher PtUt efficiency with relatively low Pt loading. This enhancement of the electro-sprayed hybrid electrode was credited to facile proton and oxygen transport to the catalytic sites, what resulted from electrode morphology and hybrid support structure. Thus, efficient diffusion of reactant gases to the catalytic sites was achieved.

Singh et al. [74] used carbon aerogel which was synthesized by impregnating Pt nano particles using the microwave assisted polyol process. Performance and stability were investigated, and results compared with those for commercially available Pt/C (JM-20) having the same Pt loading. ECSA of 73 and $56 \mathrm{~m}^{2} \mathrm{~g}^{-1}$ for Pt/CA and commercial JM-20, respectively were obtained. It was concluded that good utilization ratio of $82 \%$ could be due to the conducting and mesoporous CA support which has significant role in improving Pt activity and Pt utilization.

Lori et al. [75] employed the modified polymer-assisted deposition (mPAD) technique and synthesized molybdenum carbide $\left(\mathrm{Mo}_{2} \mathrm{C}\right)$ nano-crystallites without free carbon and used them as the catalyst support, showing ECSA of $28.4 \mathrm{~m}^{2} \mathrm{~g}^{-1}$. The reason for low ECSA was attributed to formation of aggregates during deposition, making Pt particles inaccessible for reactions.

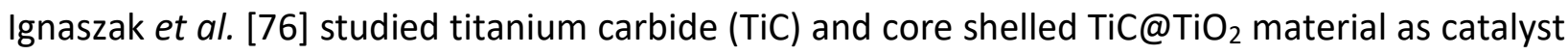
supports for $\mathrm{Pt}$ and $\mathrm{Pt}_{3} \mathrm{Pd}$ alloy ( $\mathrm{Pt} / \mathrm{TiC}, \mathrm{Pt}_{3} \mathrm{Pd} / \mathrm{TiC}, \mathrm{Pt}_{3} \mathrm{Pd} / \mathrm{TiC}_{\mathrm{CTiO}}$ ) for ORR activities. They observed 
close values of ECSA $\left(40,41\right.$ and $\left.37 \mathrm{~m}^{2} \mathrm{~g}^{-1}\right)$ for all three catalysts with no significant difference in electrochemical features. However, $\mathrm{Pt}_{3} \mathrm{Pd} / \mathrm{TiC} @ \mathrm{TiO}_{2}$ retained its activity after 500 cycles, while significant loss of activity was noticed for $\mathrm{Pt} / \mathrm{TiC}$ and $\mathrm{Pt}_{3} \mathrm{Pd} / \mathrm{TiC}$.

To overcome the drawbacks of carbon supports of PEMFC electrodes, Lobato et al. [77] prepared MEAs with two non-carbonaceous catalyst supports, SiC and SiCTiC, for PEMFC cathode side and compared the electrochemical performance with carbonaceous support. They observed that catalyst supported on novel materials ( $\mathrm{Pt} / \mathrm{SiC}, \mathrm{Pt} / \mathrm{SiCTiC}$ ) showed excellent electrochemical stability towards environmental corrosion, what was attributed to higher catalyst particle size. Also, at the end of 400 cycles, less ECSA degradation of $19.7 \%$ for Pt/SiC and $17.01 \mathrm{for} \mathrm{Pt/SiCTiC}$ was observed when compared to commercial (31.09\%) and homemade (29.82 \%) catalysts.

In an effort to find better alternative to carbon support for PEMFC catalyst, Shahgaldi et al. [78] synthesized a novel nano composite, titanium encapsulated in carbon nanosperes and carbon titanium core shell structures as cathode catalyst supports, using simple and less costly hydrothermal method. They prepared $10 \%$ and $20 \% \mathrm{TiO}_{2}$ encapsulated carbon (EC-10, EC-20) and core shell structures (CS-10, CS-20). The electrochemical study revealed that $10 \% \mathrm{TiO}_{2}$ samples (EC10, CS-10) showed higher ECSA (414 and $\left.440 \mathrm{~m}^{2} \mathrm{~g}^{-1}\right)$ than EC-20, CS-20 (280 and $\left.180 \mathrm{~m}^{2} \mathrm{~g}^{-1}\right)$, suggesting the effect of $\mathrm{TiO}_{2}$ amount on the active surface area.

Using a new synthesis method, Borchardt et al. [79] prepared Pt metal containing silicon carbide derived carbon (CDC-Pt). They reported high ECSA $\left(66 \mathrm{~m}^{2} \mathrm{~g}^{-1}\right)$ for the synthesized catalyst than conventional $\mathrm{Pt} / \mathrm{C}$ catalyst and concluded that the deposition of Pt nanoparticle onto carbon matrix provided long term stability with superior corrosion stability. Summarized results for the above category are given in Table 7.

Table 7. Carbonaceous and non-carbonaceous electrocatalysts support materials (PEMFC cathode)

\begin{tabular}{|c|c|c|c|c|}
\hline Catalyst support & Pt Loading, $\mathrm{mg} \mathrm{cm}^{-2}$ & ECSA, $m^{2} g^{-1}$ & PtUt, \% & Ref. \\
\hline Gold Nanoparticles(AuPts) & 0.012 & 234.1 & 99.5 & [65] \\
\hline Single Wall Carbon Nanotubes(SWCNT) & 0.014 & 17.8 & -- & [66] \\
\hline Multiwalled Carbon Nanotubes(MWCNT) & 0.005 & 78.4 & 84 & [67] \\
\hline Buckypaper & $0.09,0.14$ & $43.3,39.2$ & 88,84 & [68] \\
\hline Functionalized graphene sheets(FGS) & $20 w t \%$ & 109 & - & [69] \\
\hline CarbonNanoFibers (CNF) & 0.3 & 225 & -- & [70] \\
\hline Titanium oxide & 0.4 & 31.2 & -- & [71] \\
\hline Ultra Porous Carbon Fiber (UPCF) & 0.35 & 71.9 & 87.2 & [72] \\
\hline Pt/rGO/CB (H75) (hybrid support) & 0.5 & 102 & & [73] \\
\hline Carbon Aerogel(Pt/CA) & 0.4 & 73 & - & [74] \\
\hline Molybdenum Carbide $\left(\mathrm{Pt} / \mathrm{Mo}_{2} \mathrm{C}\right)$ & 0.096 & 28.4 & - & [75] \\
\hline $\mathrm{TiC}_{1} \mathrm{TiC} @ \mathrm{TiO}_{2}\left(\mathrm{Pt}-\mathrm{TiC}, \mathrm{Pt}_{3} \mathrm{Pd}-\mathrm{TiC}-\mathrm{TiO}_{2}\right)$ & 0.048 & 40,36 & - & [76] \\
\hline SiC, SiCTiC (Pt/Sic, Pt/SiCTiC) & 0.6 & $13.36,13.20$ & & [77] \\
\hline $\mathrm{TiO}_{2}, \mathrm{C}-\mathrm{TiO}_{2}\left(\mathrm{Pt} / \mathrm{TiO}{ }_{2}, \mathrm{Pt} / \mathrm{C}-\mathrm{TiO}_{2}\right)$ & 0.1 & 414,440 & & [78] \\
\hline Si-CDC (Silicon carbide derived carbon) & $12 \mathrm{wt} \%$ & 66 & & [79] \\
\hline
\end{tabular}

\section{Developing Pt metallic alloy and Pt-free catalysts}

Pt metal is alloyed with other elements to decrease the overall cost of electrodes. Several studies have been performed to obtain nearly equivalent or better catalytic activity through the introduction of Pt based binary systems such as Pt-Ni, Pt-Fe, and Pt-Co by varying the proportion of $\mathrm{Pt}$ and the alloying metal. In addition, the performance of some Pt free catalysts has also been explored [80,81]. 
Using simple chemical reduction method, Wu et al. [82] prepared $20 \mathrm{wt} \% \mathrm{Pt}$ and nickel (Ni) catalyst with XC-72 conducting furnace black (PtNi/XC-72) and graphene (PtNi/graphene) as carbon supports. From results of chemical characterization, they found that ECSA of catalyst samples are in the following order: Pt/XC-72 < PtNi/graphene $<\mathrm{PtNi} / \mathrm{XC}-72$.

Owing to their special electrical properties, $\mathrm{PtNi} / \mathrm{XC}-72$ and $\mathrm{PtNi} / \mathrm{graphene}$ electrodes showed better catalytic activity towards oxygen reduction when compared with Pt/XC-72. PtNi/graphene showed better performance than PtNi/XC-72. Due to enhanced catalyst carbon interaction and high graphite component, graphene has the potential to provide much higher durability than XC-72.

Sahoo et al. [83] synthesized doped porous carbon (DPC) with nitrogen and sulphur in a simple and green one-pot process from ionic liquid as the sole source precursor and used as the non-Pt cathode catalyst in PEMFC. The results of half-cell and full cell studies were compared with $\mathrm{Pt}$ decorated DPC (Pt/DPC). The ECSA for Pt/DPC and commercial Pt/C after ignoring the role of electric double layer formed between electrode and electrolyte, were 46.88 and $112.34 \mathrm{~m}^{2} \mathrm{~g}^{-1}$ with $\mathrm{Pt}$ utilization efficiency $98.2 \%$ and $60.2 \%$, respectively. The even distribution of Pt nanoparticles over high surface area and porous support of doped carbon material is stated as a reason for 2.5 times higher ECSA for Pt/DPC when compared to commercial Pt/C.

Wang et al. [84] synthesized a variety of Pt-Ni alloy catalysts by potentiostatic electrodeposition. They use an orthogonal array to optimize deposition parameters. Particularly, the electrochemical performance of $\mathrm{Pt}-\mathrm{Ni}$ alloy catalysts was optimized by dealloying treatment experiment conducted at $0.35 \mathrm{~V}, 20 \mathrm{~min}$ at $50^{\circ} \mathrm{C}$. The results indicated that the deposition time has the most significant impact on the performance of Pt-Ni alloy catalysts. The prepared sample (Pt-Ni) showed the highest ECSA value of $81.7 \mathrm{~m}^{2} \mathrm{~g}^{-1}$ with the catalyst loading of $0.329 \mathrm{mg} \mathrm{cm}^{-2}$ (Pt loading of $0.3 \mathrm{mg} \mathrm{cm}^{-2}$, Ni loading of $0.029 \mathrm{mg} \mathrm{cm}^{-2}$ ). Pt-Ni catalysts were dealloyed by rapid potential cycling, which resulted in a significant refinement of morphology and enhancement of electrocatalytic activity. The sample with low $\mathrm{Ni}$ atomic ratio was not suitable for the rapid dealloying treatment.

$\mathrm{Pt}-\mathrm{Cu}$ (platinum copper alloy) has been studied as a catalytically active material with high surface area, porous platinum structure and hydrogenation promoting property [85].

Bele et al. [86] demonstrated the application of stable and highly active $\mathrm{PtCu}_{3}$ nanoparticles on the carbon support. The Pt-skin $\mathrm{PtCu}_{3}$ alloy catalyst was fabricated with core shell nanoparticles having intermetallic ordered shell at a disordered core that is tightly embedded into a carbon support. Consistent ECSA of about $45 \mathrm{~m}^{2} \mathrm{~g}^{-1}$ is reported with utilization much higher than those already reported in the literature for $3 \mathrm{~nm}$ Pt nanoparticles on high surface area carbon supported electrodes. The thermal annealing enables Pt-skin and intermetallic orderings, which are favorable for enhanced activity. The stability is attributed to the firm embedding of Pt-Cu into a heterogeneous carbon matrix caused by the partial oxidation and xerogelation.

Mani et al. [87] proposed the technique of surface dealloying as an effective strategy to modify the surface electrocatalaytic properties of platinum. The copper $(\mathrm{Cu})$ surface atoms are dealloyed from $\mathrm{Pt}_{25} \mathrm{Cu}_{75}$ alloy precursor compound by electrochemical dissolution (voltammetric dealloying to prepare the active catalyst phase). This novel catalyst yielded an ECSA of $75 \mathrm{~m}^{2} \mathrm{~g}^{-1}$.

Hong et al. [88] fabricated a novel electrode, Pd/C@Pt $t_{\text {skin }}(\mathrm{C}-\mathrm{U})$, with electrospun structure by using electrospinning and under potential deposition (UPD) techniques. By in situ deposition of Pt on the surface of Pd-NP in the electrospun $\mathrm{Pd} / \mathrm{C}$ catalyst layer, they observed that almost all Pt shells become accessible for reactant gases and TPB is optimized with Pt loading of $19 \mathrm{mg} \mathrm{cm}^{-2}$. The $\mathrm{C}-\mathrm{U}$ electrode delivered higher peak power density $\left(0.62 \mathrm{~W} \mathrm{~cm}^{-2}\right)$ than conventional electrode $\left(0.55 \mathrm{~W} \mathrm{~cm}^{-2}\right)$ at Pt loading of $100 \mathrm{mg} \mathrm{cm}^{-2}$. Owing to the nearly 5-fold Pt loading, the conventional electrode showed 
better performance than C-U electrode at low current density, however at high current density there was a significant loss of voltage. This was due to the increased oxygen transfer resistance close to $\mathrm{Pt}$ surface. Summarized results for the above category are given in Table 8.

Table 8. Developing Pt metallic alloy and Pt-free catalysts

\begin{tabular}{ccccc}
\hline Pt metallic alloy \& Pt free metal & Pt loading, $\mathrm{mg} \mathrm{cm}^{-2}$ & $\mathrm{ECSA}, \mathrm{m}^{2} \mathrm{~g}^{-1}$ & $\mathrm{PtUt}, \%$ & References \\
\hline $\mathrm{PtNi} / \mathrm{XC}-72$ & 0.2 & 93 & - & {$[82]$} \\
\hline $\mathrm{Pt} / \mathrm{DPC}$ & 0.2 & 112 & 98 & {$[83]$} \\
\hline $\mathrm{Pt}-\mathrm{Ni}$ alloy & 0.3 & 81 & - & {$[84]$} \\
\hline $\mathrm{Pt}-\mathrm{CU}_{3}$ & 0.025 & 45 & - & {$[86]$} \\
\hline $\mathrm{Pt}_{25} \mathrm{Cu}_{75}$ & 0.169 & 75 & - & {$[87]$} \\
\hline $\mathrm{C}-\mathrm{U}$ electrode & 330 & 92.3 & - & {$[88]$} \\
\hline
\end{tabular}

\section{Optimization approaches for DMFC cathode}

Some approaches for optimizing Pt utilization in DMFC cathode are described below.

\section{Reducing Pt loading and decreasing Pt particle size}

Wang et al. [89] observed that addition of $\mathrm{NaOH}$ to aqueous $\mathrm{Nafion}^{\circledR}$ solution suppressed aggregation of large particles and led to smaller agglomerate particle size with uniform distribution of Pt elements in the cathode catalyst layer. Further, they obtained improved ECSA $\left(13.94 \mathrm{~m}^{2} \mathrm{~g}^{-1}\right)$ and better performance in DMFC.

To enhance Pt utilization, You et al. [90] adopted multi step reduction, Pt/C-nR ( $\mathrm{n}=$ number of reduction steps), to synthesize Pt catalyst with ultra-high Pt loading up to $85 \%$. CV results revealed that Pt/C-2R catalyst exhibited higher PtUt of $90 \%$ when compared to Pt/C-1R (60\%) with the same $\mathrm{Pt}$ loading. Although Pt particles size appears to be larger for Pt/C-1R than Pt/C-nR, the stacked microstructure in Pt/C-1R is stated to favor higher PtUt.

Wang et al. [91] investigated electrochemical oxidation of methanol and reduction of oxygen on the commercial Pt/C catalyst. High catalytic current was observed for ORR with ECSA of $41 \mathrm{~m}^{2} \mathrm{~g}^{-1}$.

To improve DMFC performance, Pu et al. [92] utilized fabricated Pt nanorod assemblies in double layered cathode with a catalyst loading of 1.0 and $2.0 \mathrm{mg} \mathrm{cm}^{-2}$ and observed significant increase in ECSA $\left(35.5 \mathrm{~m}^{2} \mathrm{~g}^{-1}\right)$ and catalyst utilization. The improvement in performance is attributed to the reduction of charge transfer resistance in DMFC, enabling more efficient Pt loading and improving performance of MEA. The increased ECSA is attributed to the reduced size of Pt particles, loose construction of Pt nanorods and embedding of nanorods in the catalyst layer.

\section{Optimization of catalyst parameters}

Krishnamurthy et al. [93] studied the performance of DMFC by varying the content of Nafion ${ }^{\circledR}$ in anode $\mathrm{CL}$ while keeping it constant on cathode. The optimized results showed the highest catalyst utilization of $65 \%$ at $0.8 \mathrm{Nafion}^{\circledR}$ to carbon (N/C) ratio. Further increase of Nafion ${ }^{\circledR}$ content was reported to result in pore blocking of the catalyst layer which leads to decrease in performance of DMFC.

Krishnamurthy et al. [94] studied the influence of PTFE content of anode and cathode CLs on DMFC performance. They examined 5, 10, 20, $30 \%$ PTFE content in cathode $\mathrm{CL}$ with anode having constant PTFE content of $20 \%$. They observed the highest catalyst utilization of $65.54 \%$ for $20 \%$ PTFE and concluded that $20 \%$ PTFE content in the cathode catalyst layer resulted in the maximal catalyst utilization. They also concluded that further increase in PTFE content to $30 \%$ leads to the 
blocking of pores of $\mathrm{CL}$, thus reducing oxygen transportation and water removal. The same authors [95] also studied the catalyst utilization by varying Nafion ${ }^{\circledR}$ content. $20 \% \mathrm{Pt} / \mathrm{C}, 40 \% \mathrm{Pt} / \mathrm{C}$ and platinum black were used as cathode catalysts and the Nafion ${ }^{\circledR}$ content was optimized for each. Based on CV results, the highest value of catalyst utilization of $65 \%$ for $33 \%$ constant Nafion ${ }^{\circledR}$ content with $40 \% \mathrm{Pt} / \mathrm{C}$ catalyst layer was obtained. No significant influence of $\mathrm{Nafion}^{\circledR}$ content on platinum black catalyst was also observed.

Matar et al. [96] investigated the effect of thickness of cathode catalyst on DMFC performance. They considered $8.4 \mu \mathrm{m}$ thickness layers as standard/base thickness for both anode and cathode with same Pt loadings. Two additional cathode catalyst layers with 19 and $44 \mu \mathrm{m}$ were examined. The authors observed decrease of ECSA as thickness of cathode catalyst layer increased and found higher ECSA of $282.88 \mathrm{~cm}^{2} \mathrm{mg}^{-1}$ for the standard/base case $(8.4 \mu \mathrm{m})$.

Using citrate stabilized method, Jiang et al. [97] prepared $60 \% \mathrm{Pt} / \mathrm{C}$ catalyst by varying carbon supports and reductants (Pt/XC-72, Pt/BP2000, Pt/XC-72R). They observed that Pt/BP2000 support resulted in higher ECSA $\left(66.46 \mathrm{~m}^{2} \mathrm{~g}^{-1}\right)$ with improved catalyst utilization. The difference in performance was attributed to the addition of chloroplatinic acid solution to citrate which contributed to formation of small Pt particles corresponding to large specific surface area with high ECSA and catalytic activity.

Moore et al. [98] investigated catalytic activity of DMFC in terms of morphology of porous cathode catalyst substrate. They synthesized three electrocatalysts, i.e. Pt/C-Celatum (a macro porous carbon substrate), Pt/CMK-3 (a mesoporous carbon substrate), and Pt/Vulcan XC-72 (a micro porous carbon substrate). After CV studies, they observed major variation between active surface area and total surface area for Nafion ${ }^{\circledR}$ impregnated sample (Pt/C-Celatum). It was concluded that the difference is due to reduced contact between Nafion ${ }^{\circledR}$ electrolyte and catalyst surface, blockage of the pores, and poor accessibility of protons between crystalline platinum and carbon substrate, which all led to low Pt utilization.

Zhao et al. [99] employed an electrochemical technique to investigate the influence of Nafion ${ }^{\circledR}$ ionomer content $(10,20,30,40$, and $50 \mathrm{wt} \%)$ catalyst layers on the cathode performance. They found the highest ECSA $\left(27 \mathrm{~m}^{2} \mathrm{~g}^{-1}\right)$ and catalyst utilization (40\%) at $30 \mathrm{wt} \%$ Nafion ${ }^{\circledR}$ content with less difference between the highest and lowest ECSA and concluded that Nafion ${ }^{\circledR}$ content has less effect on ECSA and PtUt in 10-50 wt\% range. Figure 8 illustrates the effect of Nafion ${ }^{\circledR}$ content on ECSA and Pt catalyst utilization.

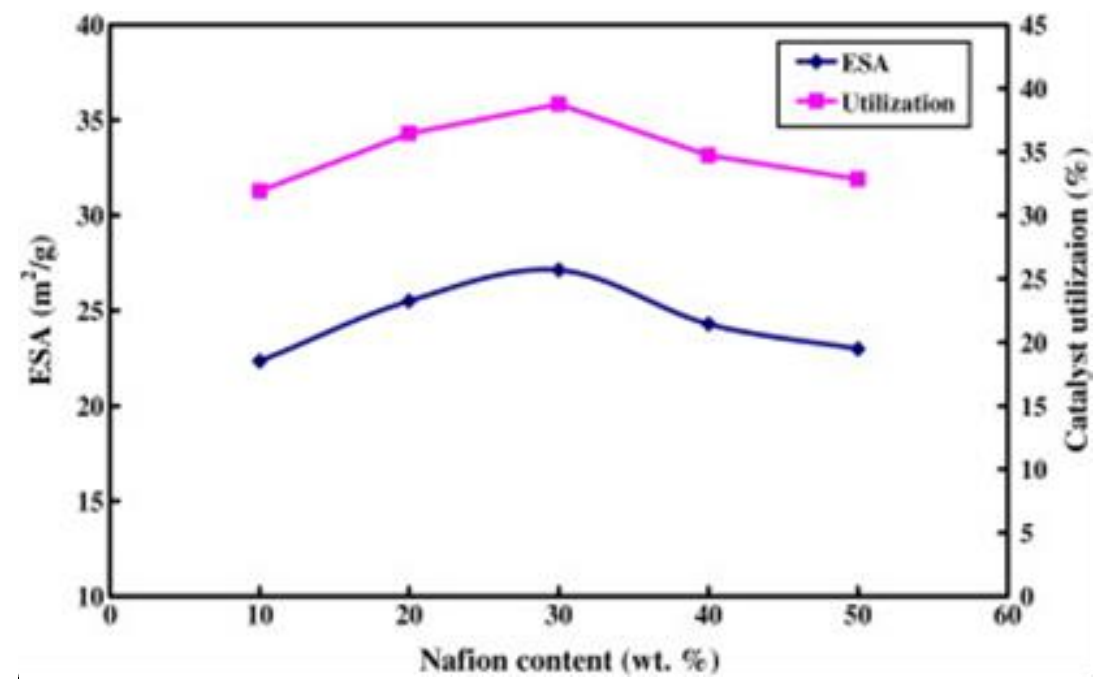

Figure 8. Effect of Nafion ${ }^{\circledR}$ content on Pt utilization and ECSA (marked as ESA on the graph). Reproduced from [99] with permission from Elsevier 


\section{Using various novel catalyst support materials}

Wang et al. [100] fabricated DMFC cathode using high surface area SWCNT (Pt/SWCNT) to increase the triple phase boundary sites. Pt/SWCNT was prepared using ion exchange (IE) method and the performance with borohydride $(\mathrm{BH})$ synthesis method was compared. They observed improved Pt utilization and concluded that entire catalyst particles were loaded on SWCNT support, being well dispersed (by IE method) and electrochemically active.

Chen et al. [101] used microwave digestion modified carbon nanotubes (CNT) on CC as the catalyst support. Larger ECSA than the others were found, which is attributed to higher Pt dispersion and uniform distribution of Pt nanoparticles.

Yaldagard et al. [102] studied the performance of Pt electrocatalyst supported on the protonated polyaniline (PANI) coated tungsten carbide (WC) nano composite and compared the results with the commercial Pt/C electrocatalyst. High Pt utilization of $77 \%$ compared to the commercial one was found, and this improvement was attributed to the synergic effect between Pt nanoparticles and WC.

Jafri et al. [103] synthesized nitrogen doped graphene to support Pt catalyst. They used MWCNT spacer to remove face to face agglomeration, what cleaned graphene sheets. Two types of samples, Pt/NGA800+MWCNT, Pt/NG180+MWCNT, were prepared using thermal solid state and hydrothermal methods and compared the results with samples without MWCNT spacer (Pt/NGA800, Pt/NG180). The authors observed $10 \%$ improvement in ECSA and 55 and $54 \%$ Pt utilization and concluded that the addition of MWCNT spacer provided good accessibility to the catalyst active site and nitrogen doped CNT, what resulted in decomposition of reactive intermediates like $\mathrm{H}_{2} \mathrm{O}_{2}$ into $\mathrm{O}_{2}$ during ORR.

Algere et al. [104] investigated sulfurized carbon xerogels (S-CXG) as the support material for Pt. The highest catalytic activity was observed for Pt/CXG-3S (3 wt\% sulphur content) because of right balance of high ECSA $\left(59.0 \mathrm{~m}^{2} \mathrm{~g}^{-1}\right)$ and good intrinsic activity. It was found that Pt/CXG-3S exhibited better catalytic activity than Pt/CXG without sulfurization or Vulcan.

Tesfu et al. [105] investigated the use of mesoporous structured hollow graphitized carbon spheres (HGS) as DMFC cathode catalyst support material in $100-150^{\circ} \mathrm{C}$ temperature range. Pt/HGS catalyst showed improved ECSA and double layer capacity values which is attributed to higher accessibility of Pt particles. However, large decrease in ECSA (60\% compared to $14 \%$ for Pt/Vulcan) was observed at thermal treatment beyond $850{ }^{\circ} \mathrm{C}$. They inferred that this does not correlate with increased particle size and concluded that during thermal treatment, the decomposition of HGS carbon structure resulted in the blockage of pores, making Pt active sites inaccessible to the electrolyte.

\section{Developing Pt metallic alloy and Pt-free catalysts}

Hosseini et al. [106] synthesized $\mathrm{Ni} / \mathrm{Pt} / \mathrm{C}$ electrocatalyst using sodium borohydride as the reducing agent and sodium dodecyl sulphate (SDS) as a structure directing agent. This electrode exhibited improved catalytic activity than NiPt/C catalyst. ECSA of $41 \%$ (Ni/Pt/C) and $16.8 \mathrm{~m}^{2} \mathrm{~g}^{-1}$ $(\mathrm{NiPt} / \mathrm{C})$, respectively, were recorded. Core shell structure of the prepared catalyst was stated as the reason for the increased ECSA and current density. Summarized results for the above category are given in Table 9. 
Table 9. Platinum utilization for DMFC cathode

\begin{tabular}{|c|c|c|c|c|}
\hline GDE/structure/support/membrane/ parameters & Pt loading, $\mathrm{mg} \mathrm{cm}^{-2}$ & $E C S A, m^{2} g^{-1}$ & PtUt, \% & Ref. \\
\hline \multicolumn{5}{|l|}{ Reducing platinum loading and decreasing Pt size } \\
\hline Effect of Nafion ${ }^{\circledast}$ ionomer aggregation & 6.3 & 13.94 & & [89] \\
\hline Multi Reduction method Pt(76)/C-1R /Pt(76)/C-2R & 2.0 & $60.2 / 65.3$ & $68 / 90$ & [90] \\
\hline PtNT & - & 41 & - & [91] \\
\hline Double layered catalyst based MEA & $1.0,2.0$ & $35.5,34.3$ & & [92] \\
\hline \multicolumn{5}{|l|}{ Optimization of catalyst parameters } \\
\hline Nafion ${ }^{\circledR}$ to carbon (N/C) ratio & 2.0 & - & 6 & [93] \\
\hline Effect of Polytetrafluoroethylene(PTFE) & 2.0 & 57.0 & 65.54 & [94] \\
\hline Effect of Nafion ${ }^{\circledR}$ content & $40 \mathrm{wt} \%$ & 67.03 & 65.12 & [95] \\
\hline Cathode catalyst layer thickness & 1 & 28.3 & - & [96] \\
\hline $\begin{array}{l}\text { Citrate-stabilized method with different reductants } \\
\text { and carbon supports (Pt/BP2000) }\end{array}$ & 2.8 & 66.46 & - & [97] \\
\hline $\begin{array}{l}\text { Effect of the cathode catalyst substrate morphology } \\
\text { (Pt/Vulcan XC-72) }\end{array}$ & 1 & 33.4 & $25.1 \%$ & [98] \\
\hline Influence of ionomer content( $30 \%$ Nafion $\left.{ }^{\circledR}\right)$ & 2 & 28 & $40 \%$ & [99] \\
\hline \multicolumn{5}{|l|}{ Using various novel catalyst support materials } \\
\hline Pt/SWCNT & $11.8 w t \%$ & $129.6 \mathrm{~cm}^{2}$ & $90 \%$ & {$[100]$} \\
\hline Pt/MWCNT & 0.3 & $23.9 \mathrm{~cm}^{2}$ & $25.1 \%$ & [101] \\
\hline Pt/PANI/WC/C & 4 & 20.46 & $77 \%$ & [102] \\
\hline $\begin{array}{l}\text { Nitrogen doped graphene with MWCNT spacer } \\
\text { (Pt/NG1800+MWCNT) }\end{array}$ & 0.42 & 47 & $55 \%$ & [103] \\
\hline Carbon Xerogels (CXG) & $20 \mathrm{wt} \%$ & 59.0 & - & {$[104]$} \\
\hline HGS & 2 & & & [105] \\
\hline
\end{tabular}

\section{Optimization approaches for DMFC anode}

Some approaches to optimizing Pt utilization in DMFC anode are given below.

\section{Optimization of catalyst parameters}

Liang et al. [107] electrochemically deposited Pt nanowires into partial layer of nano Nafion ${ }^{\circledR}$ membrane and formed Pt nanowire network. CV tests showed large ECSA for Pt Nafion ${ }^{\circledR}$ integrated electrodes than conventional E-TEK electrode. Initial results revealed higher ECSA for Pt-Nafion ${ }^{\circledR}$ integrated electrode and a low rate of methanol. Utilization of methanol during the discharge of cell and increased membrane tortuosity are attributed as reasons for enhancement of the catalytic activity.

Scibioh et al. [108] explored the ionomer coating (1, 2, 5 wt\%) on Ketjen Black EC 300JD (EC), Vulcan XC-72R (VC) and Black Pearls 2000C (BP) carbon supports with different surface area and pore characteristics. They observed better performance for EC5 (Ketjen Black EC 300JD coated with 5 wt\% Nafion $^{\circledR}$ ) due to extension of TPB, resulting from the improved interaction between catalyst particles and ionomer.

Pu et al. [109] employed a thermal imprint technology to prepare passive DMFC using Nafion ${ }^{\circledR}$ 115 membrane on the anode side. The anode catalyst utilization was found to be improved with improved ECSA, which is credited to the additionally increased roughness factor of membrane. They concluded that catalyst utilization at the anode can be improved by using patterned membranes $\mathrm{H}_{4}$, $H_{6}, H_{10}$, with pore depths of $4,6,10 \mu \mathrm{m}$ and roughness factors $2.7,4.6,5.4$ and observed the highest ECSA for $\mathrm{H}_{10}$ membrane.

Kaplan et al. [110] studied platinum utilization on methanol-oxidation surface by varying $\mathrm{Pt}: \mathrm{Ru}$ surface composition. Carbon-supported catalysts with iridium-nickel cores and varying atomic-ratio platinum ruthenium shells $\left(\mathrm{Pt}_{25} \mathrm{Ru}_{75}\right.$ to $\left.\mathrm{Pt}_{80} \mathrm{Ru}_{20}\right)$ were synthesized. The ECSA values obtained for the studied catalysts were $50 \mathrm{~m}^{2} \mathrm{~g}_{\text {PtRu }}{ }^{-1}$ for the commercial catalyst, $35 \mathrm{~m}^{2} \mathrm{~g}_{\text {PtRulr }}{ }^{-1}$ for $\mathrm{Pt}_{13} \mathrm{Ru}_{22}, 28 \mathrm{~m}^{2} \mathrm{~g}_{\text {PtRulr }}{ }^{-1}$ 
for $\mathrm{Pt}_{16} \mathrm{Ru}_{14}, 27 \mathrm{~m}^{2} \mathrm{~g}_{\text {PtRulr }}{ }^{-1}$ for $\mathrm{Pt}_{23} \mathrm{Ru}_{9}$, and $27 \mathrm{~m}^{2} \mathrm{~g}_{\text {PtRulr }}{ }^{-1}$ for $\mathrm{Pt}_{28} \mathrm{Ru}_{7}$. The highest mass activity was obtained for $\mathrm{Pt}_{13} \mathrm{Ru}_{22}$ despite its $23 \%$ lower surface activity compared to $\mathrm{Pt}_{16} \mathrm{Ru}_{14}$. This was explained by better $\mathrm{Pt}$ utilization of $\mathrm{Pt}_{13} \mathrm{Ru}_{22}$ compared to $\mathrm{Pt}_{16} \mathrm{Ru}_{14}$. This result demonstrated higher platinum utilization of the core shell structure and possible reduction of Pt loading with use of core-shell catalysts. The authors stated that further improvement can be achieved by enhancing Pt utilization with the highest surface activity and optimal PtRu ratio. This can be done by reducing Pt wt\% while adjusting ruthenium wt\% accordingly, in order to maintain the favorable surface $\mathrm{Pt} / \mathrm{Ru}$ ratio.

Lin et al. [111] used a newly developed active screen plasma (ASP) technique to examine the effect of temperature and treatment duration on the growth of Pt nanowires on the GDL surface. They observed that starting from $100{ }^{\circ} \mathrm{C}$ temperature onwards, ECSA increased expressively, showing a maximum at $150^{\circ} \mathrm{C}$, and decreased before further increase of temperatures between 180 and $210^{\circ} \mathrm{C}$. The ECSA for samples treated at $150{ }^{\circ} \mathrm{C}$ was observed to be $65 \%$ higher when compared with untreated one, indicating the influence of temperature on Pt nanowire growth.

Alcaide et al. [112] studied the influence of solvent on the catalyst inks for active layer manufacturing in DMFC applications. Two types of solvents, 2-propanol (IPA) and n-butyl acetate (NBA), have been used. The ECSA determined by CO stripping were 52.4 and $47.3 \mathrm{~m}^{2} \mathrm{~g}^{-1}$, i.e. about $11 \%$ greater ECSA was found for NBA than IPA. Results indicate that the ECSA of CL formulated with NBA was higher than that formulated with IPA. This clearly indicates that secondary pores in the catalyst formulated with NBA make accessible a greater surface area of the catalyst.

\section{Using various novel catalyst support materials}

Han et al. [113] tested the performance of DMFC anode with three different support materials. They prepared Pt-Ru electrocatalyst with acetylene black, Vulcan XC-72 and Ketjin Black EC-300J as carbon supports. They found small particle size, good dispersion and high methanol oxidation activity for Ketjin Black carbon support with 80 wt\% Pt content, thus leading to higher ECSA and better Pt utilization. PtRu supported on acetylene black has the lowest activity because of large clusters of nanoparticles caused by agglomeration. In contrast, Pt-Ru supported on Ketjen Black having better dispersion, exhibited three-fold increase in catalytic activity when compared to P-Ru/acetylene black.

Sun et al. [114] synthesized OMC-FT, OMC-F ordered mesoporous carbon with varying pore framework. Higher ECSA and good stability was observed for OMC-FT/Pt $\left(62.96 \mathrm{~m}^{2} \mathrm{~g}^{-1}\right)$ than OMCs$\mathrm{F} / \mathrm{Pt}\left(54.36 \mathrm{~m}^{2} \mathrm{~g}^{-1}\right)$. Uniform dispersion of Pt nanoparticles resulted from high surface area and increased meso-porosity lead to high Pt utilization.

To avoid the waste of noble catalysts, Carmo et al. [115] used nitric acid incorporated carbon black support to prepare $\mathrm{Pt} / \mathrm{Ru}$ electrocatalyst (PtRu/C- $\mathrm{HNO}_{3}$ ). They observed better nano particle distribution on the catalyst support with high affinity and more exposed area of Ru towards species containing oxygen, leading to better ECSA of $104 \mathrm{~m}^{2} \mathrm{~g}^{-1}$ with better Pt utilization.

Luo et al. [116] prepared a Pt-Nafion ${ }^{\circledR}$ high performance catalyst carbon support functionalized by perflourosulfonic acid and compared the results with Pt/O-C and Pt-Nafion ${ }^{\circledR} / \mathrm{C}$ catalysts. They observed $30 \%$ higher ECSA of $104.9 \mathrm{mg} \mathrm{cm}^{-2}$ for Pt-Nafion ${ }^{\circledR} / \mathrm{C}$ catalyst when compared to Pt/O-C. The presence of Nafion ${ }^{\circledR}$ leads to higher dispersion of Pt nanoparticles and increased ECSA.

Liu et al. [117] used multi walled carbon nanotubes doped with phosphorous (P-MWCNT) as the catalyst support and prepared Pt/P-MWCNT electrode for DMFC. Improved Pt particles dispersion with increased intrinsic activity resulting in high Pt utilization was observed. This was attributed to change of charge density of P-MWCNT, leading to better interfacial interaction between surfaces of Pt and P-MWCNT. 
Sun et al. [118] designed and synthesized 1D open Pt structures with porous surface. Using polyelectrolyte-modified $\mathrm{FeOOH}$ nanorods as a template, they prepared hollow Pt nanotubes (PtNT). Employing the electrostatic attraction-based layer-by-layer assembly process, the self-supporting porous electrode was synthesized. ECSA of $19.6 \mathrm{~m}^{2} \mathrm{~g}^{-1}$ was observed for this electrode when compared to $16.8 \mathrm{~m}^{2} \mathrm{~g}^{-1}$ of Pt black catalyst. In spite of similar structure and composition of these electrodes, the increased ECSA was attributed to 1D porous structure of the prepared electrode.

Using chemical interfacial method, Gharibi et al. [119] prepared a composite of polyaniline (PANI) fiber doped with para-toluenesulfonic acid (PTSA) and fabricated the vulcan-polyaniline composite, C-PANI-PTSA. Pt electrocatalyst was deposited on the composite with different ratios $(10,15,20$, 25, $30 \mathrm{wt} \%)$, optimized and compared with Pt/C electrocatalyst. They found high ECSA $\left(120.5 \mathrm{~m}^{2} \mathrm{~g}^{-}\right.$ $\left.{ }^{1}\right)$ for Pt/C-20 \% PANI-PTSA electrocatalyst. C-PANI-PTSA composite exhibited better dispersion of Pt particles resulting in increased ECSA.

For depositing Pt nanoparticles, Li et al. [120] prepared a hybrid support $\mathrm{Ti}_{x} \mathrm{~S}_{\mathrm{n} 1-\mathrm{x}} \mathrm{O}_{2}-\mathrm{C}$ via thermal method with substitution of $\mathrm{Ti}^{4+}$ by $\mathrm{Sn}^{4+}$ in $\mathrm{TiO}_{2}$ lattice and observed improved $\mathrm{Pt}$ utilization with increased ECSA $\left(68.9 \mathrm{~m}^{2} \mathrm{~g}^{-1}\right)$ compared to the commercial catalyst.

Patel et al. [121] used the complexed sol-gel (CSG) process to synthesize Pt/Ru/TiN anode catalyst with titanium nitride (TiN) as the support. Higher ECSA of $59 \mathrm{~m}^{2} \mathrm{~g}^{-1}$ than the commercial catalyst was observed with uniform dispersion of $\mathrm{Pt} / \mathrm{Ru}$ on the support. It was stated that the CSG process resulted in generation of the nanocrystalline $\mathrm{Pt} / \mathrm{Ru}$ on the support.

Zhang et al. [122] used nitrogen-doped carbon nanotubes ( $\left.\mathrm{CN}_{\mathrm{x}}-\mathrm{NTs}\right)$ as the catalyst support material. They were prepared by carbonization of PPy-NT which were synthesized using methyl orange as a structure-guiding agent. ECSA values observed for these catalysts are $44.4 \mathrm{~m}^{2} \mathrm{~g}^{-1}$ (Pt/CN $-\mathrm{NTs}-600), 55.9 \mathrm{~m}^{2} \mathrm{~g}^{-1}$ (Pt/CN $\left.\mathrm{CN}_{\mathrm{x}}-\mathrm{NTs}-700\right), 94.0 \mathrm{~m}^{2} \mathrm{~g}^{-1}$ (Pt/CN $\left.\mathrm{CN}_{\mathrm{x}}-\mathrm{NTs}-800\right)$ and $71.2 \mathrm{~m}^{2} \mathrm{~g}^{-1}\left(\mathrm{Pt} / \mathrm{CN}_{\mathrm{x}}-\right.$ NTs-900). The highest catalytic activity of $\mathrm{Pt} / \mathrm{CN}_{\mathrm{x}}-\mathrm{NTs}-800$ catalyst is attributed to the optimal proportion of N-5, N-6 and N-Q.

Gao et al. [123] used graphene/Vulcan XC-72 carbon as the catalyst support and prepared platinum/graphene/Vulcan XC-72 (Pt/Gr-C) catalyst. Graphene oxide (GO) and $\mathrm{H}_{2} \mathrm{PtCl}_{6}$ were simultaneously reduced in ethylene glycol. Then, through ultra-sonication in aqueous solution, low-cost Vulcan XC-72 carbon was incorporated between graphene sheets. ECSA values of $37.9 \mathrm{~m}^{2} \mathrm{~g}^{-1}(\mathrm{Pt} / \mathrm{C})$, $41.8 \mathrm{~m}^{2} \mathrm{~g}^{-1}(\mathrm{Pt} / \mathrm{Gr})$ and $50.5 \mathrm{~m}^{2} \mathrm{~g}^{-1}(\mathrm{Pt} / \mathrm{Gr}-\mathrm{C})$, respectively were obtained. The best result for Pt/Gr-C was attributed to the inhibition effect of Vulcan XC-72 carbon sphere on the overlap of graphene and smaller particle size.

To increase the methanol oxidation activity of Pt catalyst, Jeon et al. [124] developed Pt/WC/C catalyst and analyzed electrochemical properties. CO-stripping studies revealed ECSA of $3.8 \mathrm{~m}^{2} \mathrm{~g}^{-1}$ for Pt/WC/C catalyst and $5.9 \mathrm{~m}^{2} \mathrm{~g}^{-1}$ for the conventional Pt/C. Higher ECSA $\left(7.5 \mathrm{~m}^{2} \mathrm{~g}^{-1}\right)$ was recorded for Pt/WC/C and not much different ECSA was observed for Pt/C $\left(5.6 \mathrm{~m}^{2} \mathrm{~g}^{-1}\right)$ when hydrogen adsorption method was used. Difference in ECSA observed by two methods was due to $\mathrm{H}^{+}$spill-over at the synthesized $\mathrm{Pt} / \mathrm{WC} / \mathrm{C}$ catalyst. Further, from $\mathrm{CO}$ stripping studies the reduced potential of $0.68 \mathrm{~V}$ for the synthesized catalyst $\mathrm{Pt} / \mathrm{WC} / \mathrm{C}$ than $\mathrm{Pt} / \mathrm{C}(0.8 \mathrm{~V})$ was found, indicating improved $\mathrm{Pt} / \mathrm{WC} / \mathrm{C}$ activity towards $\mathrm{CO}$ electro-oxidation.

\section{Developing Pt metallic alloy and Pt-free catalysts}

Giorgi et al. [125] deposited PtAu bimetallic nanoparticles on carbon nano fibers (CNF) directly grown on graphite paper and observed three times increase in the performance than for the commercial carbon support electrode having Pt utilization of $11 \%$. The augmented catalytic action of this 
electrode when compared to PtRu catalyst was attributed to increased utilization of catalyst particles, which leads to superior ability towards methanol oxidation. The specific morphology of platelet CNF reduces amalgamation and regulates a robust foundation of catalyst nanoparticles on the substrate. In addition, the surface of the nanofibers is encompassed by functional groups which enable better oxidation, leading to the reduction of carbon-based species like $\mathrm{CO}$ that are accumulated on the electrode. Thereby Pt poisoning during cell operation is reduced and stability is enhanced.

Jang et al. [126] deposited Pt-Au alloy nanoparticles on graphene to prepare three-dimensional graphene electrodes (3D-GR/PtAu). Using the spraying and evaporation technique, Pt-Au alloy is deposited on colloidal graphene by employing the aerosol process. The ECSA (92 to $325 \mathrm{~m}^{2} \mathrm{~g}^{-1}$ ) values were found to increase with decrease in graphene oxide concentration ( 0.5 to $0.1 \mathrm{wt} \%$ ). The highest ECSA of $325 \mathrm{~m}^{2} \mathrm{~g}^{-1}$ obtained for this electrode was relatively higher than for two-dimensional graphene electrode (2D-GR/PtAu) and commercially available Pt/C catalyst. This is attributed to increased active reaction sites, resulting in greater ability towards methanol oxidation.

Chang et al. [127-130] demonstrated anode catalyst for DMFC methanol electro oxidation using $\mathrm{Ni}_{2} \mathrm{P}$, CoP promoters. They synthesized Pt-Ni $2 \mathrm{P}, \mathrm{PtRu}-\mathrm{Ni}_{2} \mathrm{P}, \mathrm{Pt}-\mathrm{CoP}$ and PtRu-CoP by Co-depositing $\mathrm{Ni}_{2} \mathrm{P}, \mathrm{CoP}$ promoters with $\mathrm{Pt}$ and $\mathrm{PtRu}$ on carbon support and optimized the electrodes by varying the amount of promoters (10, 20 30, 40 and $50 \%)$. From H-adsorption and CO stripping measurements, they observed maximum ECSA for $30 \%$ loading promoter for $\mathrm{Pt}-\mathrm{Ni}_{2} \mathrm{P}, \mathrm{Pt}-\mathrm{CoP}$ catalyst and $40 \%$ loading of promoter for $\mathrm{PtRu}-\mathrm{Ni}_{2} \mathrm{P}$ and $\mathrm{PtRu}-\mathrm{CoP}$, respectively. The $\mathrm{CV}$ results are shown in Figure 9. The enhanced results were attributed to electron transfer between catalyst promoters and Pt, PtRu catalyst. The ECSA results are summarized in Table 10.

Table 10. Platinum utilization analysis for DMFC anode

\begin{tabular}{|c|c|c|c|}
\hline GDE/structure/support/membrane/parameters & Pt loading, $\mathrm{mg} \mathrm{cm}^{-2}$ & ECSA, $\mathrm{m}^{2} \mathrm{~g}^{-1}$ & Ref. \\
\hline Nano-Nafion ${ }^{\circledR}$ membrane & 4 & 11.5 & [107] \\
\hline Ionomer coating ( $5 \mathrm{wt} \%$ ) & $40 w t \%$ & 63.0 & [108] \\
\hline Roughness Factor(RF) & 1.0 & 45.8 & [109] \\
\hline Atomic ratio & 0.7 & 35 & [110] \\
\hline Plasma treatment conditions & - & 25.8 & [111] \\
\hline Effect of solvent: & 0.8 & 52.4 & [112] \\
\hline P-Ru/Ketjen Blank & 5 & 45.63 & [113] \\
\hline Ordered mesoporous carbon & $20 w t \%$ & $62 . .96$ & [114] \\
\hline Nitric acid functionalized CB/Vulcan XC72R- $\mathrm{HNO}_{3}$ & $20 w t \%$ & 104 & [115] \\
\hline Nafion ${ }^{\circledR}$ functionalized CB (Pt/Nafion $\left.{ }^{\circledR}-\mathrm{C}\right)$ & $20 \mathrm{mg}$ & 104.9 & [116] \\
\hline Phosphorous doped CNT(Pt/P-MWCNT) & - & 78.9 & [117] \\
\hline 1D open - Pt structures with porous surface(PtNTs) & 0.028 & 19.6 & [118] \\
\hline Pt/C-PANI-PTSA & 0.1 & 120 & [119] \\
\hline $\mathrm{SnO}_{2}-\mathrm{TiO}_{2}$ & 1 & 68.9 & [120] \\
\hline Nanostructures TiN & 0.3 & 59 & [121] \\
\hline Pt/CNx-NTS-800 & $5.3 \mathrm{wt} \%$ & 94.0 & [122] \\
\hline $\mathrm{Pt} / \mathrm{Gr}-\mathrm{C}$ & 0.019 & 50.5 & [123] \\
\hline $\mathrm{Pt} / \mathrm{WC} / \mathrm{C}$ & - & 3.8 & [124] \\
\hline Platelet Carbon Nano fiber grown on graphite paper. & 0.011 & 59 & [125] \\
\hline 3D-GR/PtAu & $20 \mathrm{wt} \%$ & 325 & [126] \\
\hline $\mathrm{Pt}-\mathrm{Ni}_{2} \mathrm{P}-30 \%$ & 5 & 69 & [127] \\
\hline PtRu-Ni ${ }_{2} \mathrm{P}-40 \%$ & 2 & 113 & [128] \\
\hline Pt-CoP-30 \% & 0.3 & 81 & [129] \\
\hline PtRu-CoP-40\% & 2 & 116 & [130] \\
\hline
\end{tabular}


a

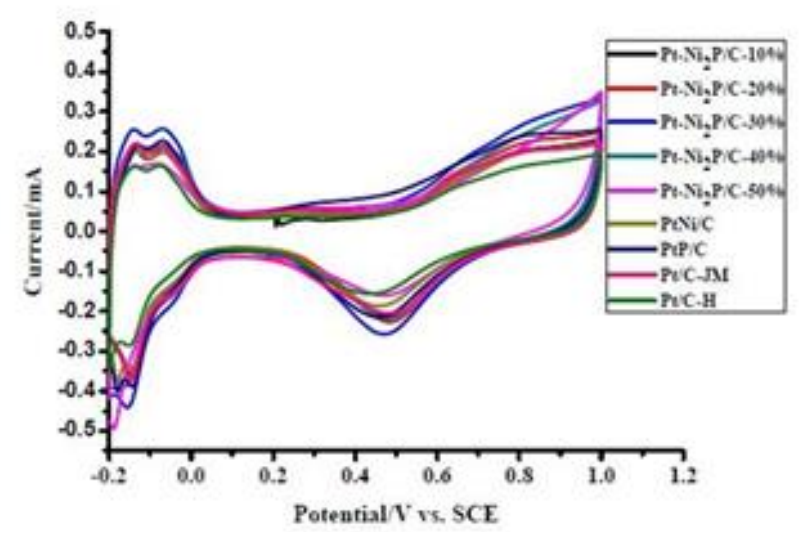

C

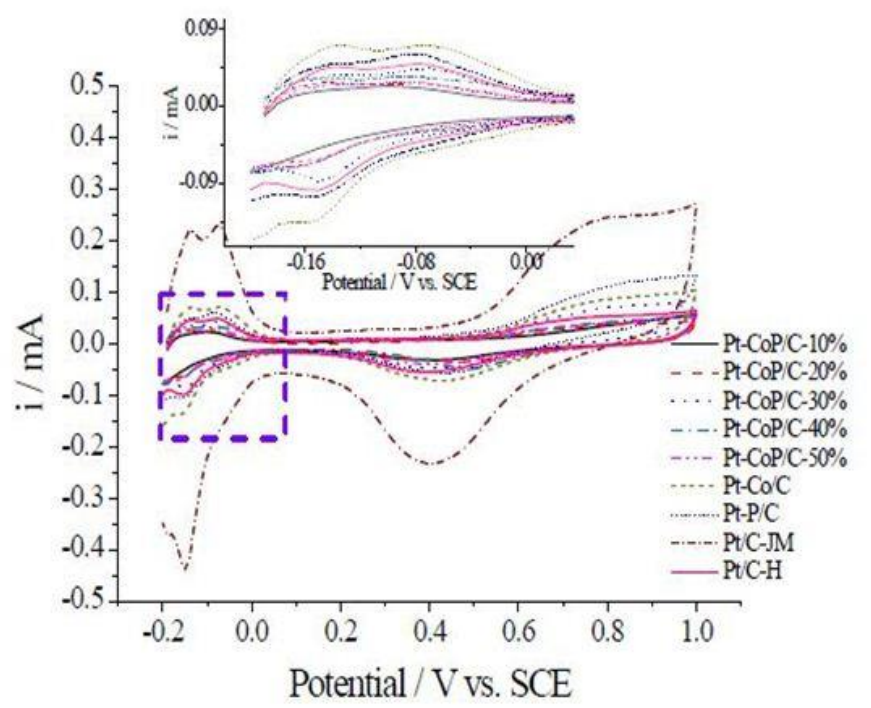

b

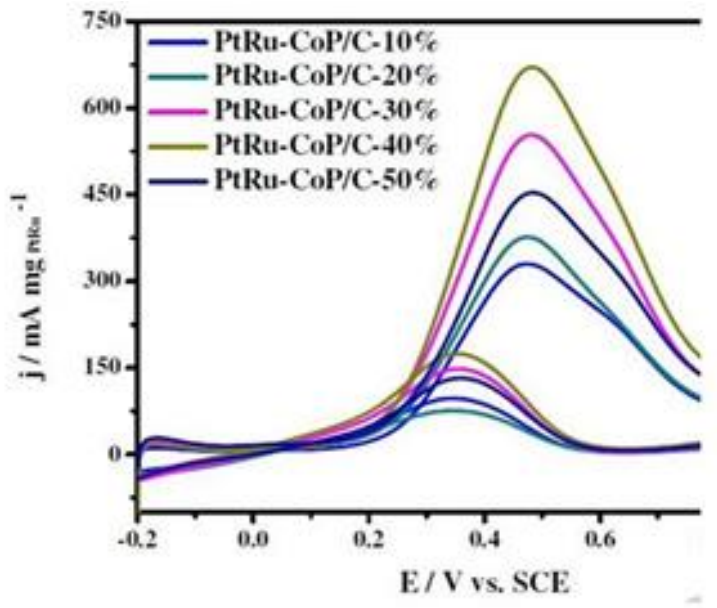

d

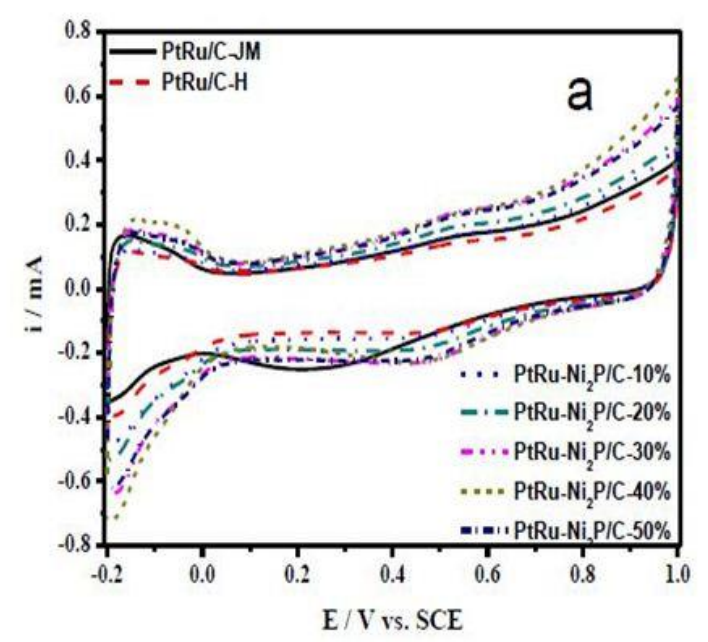

Figure 9. Cyclic voltammograms of (a) Pt-Ni 2 P (b) PtRu-CoP/C (c) Pt-CoP/C (d) PtRu-Ni $\mathrm{i}_{2} \mathrm{P}$ for varying amount of promoters (10, 20, 30, 40 and $50 \%)$.

\section{Conclusion}

This review has summarized various approaches adopted by researches over the past two decades to enhance Pt utilization efficiency and thereby reduce cost and address various other technical barriers for PEMFC's and DMFC's to become commercially viable. It is established that catalysis is a surface phenomenon on electrodes, where catalyst activity is largely governed by the dispersion of particles, particle size and the exposed percentage of particles available in the catalyst layer. For this reason, and in order to reduce Pt loading, it is essential that efforts must be made to use all Pt particles during reaction. Reducing particle size can therefore be seen as the primary focus of research so far in the area of catalyst utilization.

It is well known that the exposed percentage of the catalyst available for catalytic activity is the reciprocal of particle size. This means that reducing the particle size to below $1 \mathrm{~nm}$ levels may lead to $100 \%$ Pt utilization. However, research revealed that the porous structure of the carbon support with the pore size at approximately $2 \mathrm{~nm}$ is a hindrance. That is, reduction of Pt particle size below $2 \mathrm{~nm}$ lowers its specific activity and results in the pocketing of the particles inside the porous structure of the carbon support, rendering them inaccessible for catalyst reaction. Further, the behavior of metal particles smaller than $1 \mathrm{~nm}$ display greater interaction with the carbon support in deviation of their normal conventional behavior thereby reducing their participation in electroactivity. 
Nevertheless, the recent progress in catalyst utilization research has brought down the effective particle size of platinum-based catalyst to about 2-4 $\mathrm{nm}$ range and the percentage of exposed $\mathrm{Pt}$ particles to the range of 20-50\%. This has been achieved through the following means:

- Increasing of TPB, where electrolyte, electrode and fuel gas come into contact with each other, by optimizing the composition of the catalyst layer and catalyst distribution.

- Attainment of reduced mass transport losses by controlling pore structure and hydrophobicity especially at high current density of $C L$ to provide more electrochemical reaction area with improved gas and liquid transport pathways.

- Reducing of the interfacial resistance by tailoring $\mathrm{CL}$ and GDL, and between $\mathrm{CL}$ and membrane interfacial structures

- Designing novel methods for ordered CL preparation.

As it was established that reducing the particle size may not result in optimizing catalyst utilization, other viable alternatives need to be explored. In addition to the use of Pt and Pt alloy as a catalyst, efforts are also being carried out to investigate the application of non-Pt alloys as catalysts to reduce the overall cost of the fuel cell.

Also, it is worth mentioning here that recent research indicates stability or the life span of PEMFC as the most important factor, irrespective of Pt loading per area. This means that as long as high Pt loading contributes to increase in stability, life span and the overall effectiveness of the fuel cell, a reduction of Pt loading should not be prioritized. Nevertheless, development of Pt electrocatalyst with low Pt loading will continue to stay in the focus of active research.

\section{NOMENCLATURE}

\begin{tabular}{|c|c|c|c|}
\hline 1D & one dimensional & HD-EG & homogeneous deposition of ethylene glycol \\
\hline ASP & active screen plasma & HGS & hollow graphitized carbon spheres \\
\hline AST & accelerated stress test & $\mathrm{IE}$ & ion-exchange \\
\hline AuPt & gold nanoparticles supporting Pt & IPA & isopropyl alcohol \\
\hline $\mathrm{BH}$ & borohydride & LSV & linear sweep voltammetry \\
\hline $\mathrm{BP}$ & black pearl & MEA & membrane electrode assembly \\
\hline CA & carbon aerogels & mPAD & modified polymer-assisted deposition \\
\hline $\mathrm{CB}$ & carbon black & MPL & microporous layer \\
\hline $\mathrm{CCL}$ & cathode catalyst layer & MWCNT & multiwalled carbon nanotubes \\
\hline CCS & catalyst coated substrate & $\mathrm{N} / \mathrm{C}$ & Nafion ${ }^{\circledR}$ carbon ratio \\
\hline CC & carbon cloth & $\mathrm{NaBH}_{4}$ & sodium borohydride \\
\hline CCS-20 & compound carbon support & NCS & novel cathode structure \\
\hline $\mathrm{CL}$ & catalyst layer & NDCL & novel double catalyst layer \\
\hline CMK & a family of mesoporous material & NMP & N-Methyl-2-pyrrolidoone \\
\hline CMPL & carbon microporous layer & OMC & ordered mesoporous carbon \\
\hline CNF & carbon nanofibers & ORR & oxygen reduction reaction \\
\hline CNT & carbon nanotubes & PEMFC & proton exchange membrane fuel cell \\
\hline $\mathrm{CO}_{\mathrm{ad}}$ & adsorbed carbon monoxide & PGM & platinum group metal \\
\hline $\mathrm{CP}$ & carbon paper & PLD & pulse laser deposition technique \\
\hline CTAB & centyl trimethyl ammonia bromide & PPT & pulse plating technique \\
\hline CV & cyclic voltammetry & PtUt & platinum utilization \\
\hline CVD & chemical vapor deposition & PTFE & poly tetra flouro ethylene \\
\hline CXG & carbon xerogels & PtNP & platinum nanoparticles \\
\hline $\mathrm{DCL}$ & double catalyst layer & PtNT & platinum nanotubes \\
\hline DC & direct current & PTSA & para sulfonic acid \\
\hline DMFC & direct methanol fuel cell & rGO & reduced graphene oxide \\
\hline DPC & doped porous carbon & $\mathrm{ScCO}_{2}$ & super critical carbon dioxide \\
\hline$E / E$ & electrospinning and electrospraying & $\mathrm{SCL}$ & single catalyst layer \\
\hline
\end{tabular}




$\begin{array}{ll}\text { ECSA } & \text { electrochemical active surface area } \\ \text { EG } & \text { ethylene glycol } \\ \text { FGS } & \text { functionalized graphene sheets } \\ \text { GDE } & \text { gas diffusion electrode } \\ \text { GDL } & \text { gas diffusion layer } \\ \text { GO } & \text { graphene oxide } \\ \text { Gr } & \text { graphene } \\ \text { GSA } & \text { geometrical specific surface area }\end{array}$

$\begin{array}{ll}\text { SDS } & \text { sodium dodecyl sulphate } \\ \text { SENS } & \text { surface enriched nanosized } \\ \text { SWCNT } & \text { single walled carbon nanotubes } \\ \text { TCS } & \text { traditional catalyst structure } \\ \text { TFCL } & \text { thin film catalyst layer } \\ \text { TPB } & \text { triple phase boundary } \\ \text { UPCF } & \text { ultrafine porous carbon fibre } \\ \text { HUPD } & \text { hydrogen under potential deposition }\end{array}$

\section{References}

[1] C. Berger, Handbook of Fuel Cell Technology, Prentice-Hall, NJ, United States, 1968.

[2] T. Zhao, C. Xu, Fuel cells: direct methanol fuel cell: overview performance and operational conditions, J. Garche, Oxford: Elsevier, Amsterdam, 2009, p.381-389.

[3] S. J. Peighambardoust, S. Rowshanzamir, M. Amjadi, International Journal of Hydrogen Energy 35 (2010)9349-84.

[4] V. Mehta, J. S. Cooper, Journal of Power Sources 114 (2003) 32-53.

[5] K. V. Schaller, C. Gruber, Fuel Cells Bulletin 3 (2000) 9-13.

[6] F. Panik, Journal of Power Sources 71 (1998) 36-8.

[7] K. Sopian, W. R. Daud, Renewable Energy 31 (2006) 719- 27.

[8] S. Litster, G. McLean, Journal of Power Sources 130 (2004) 61-76.

[9] Z. Liu, L. Ma, J. Zhang, K. Hongsirikarn, J. G. Goodwin, Catalysis Reviews 55 (2013) 255-88.

[10] I.E. Stephens, A. S. Bondarenko, U. Grønbjerg, J. Rossmeisl, I. Chorkendorff, Energy and Environmental Science 5 (2012) 6744-62.

[11] U.S. Dept. of Energy. Fuel cell hand book, 7th ed., West Virginia: Office of Fossil Fuel, National Energy Technology Laboratory; October 2000.

[12] De Frank Bruijn, G.J. Janssen, PEM fuel cell materials: Costs, performance and durability. Springer, New York, 2013, p. 249-303.

[13] A.Lavacchi, H. Miller,F. Vizza, Nanotechnology in electrocatalysis for energy, Springer, New York,2013.

[14] M. S. Wilson, S. Gottesfeld, Journal Applied Electrochemistry 22(1992) 1-7.

[15] C.H. Hsu, C.C. Wan, Journal of Power Sources (2003) 268-73.

[16] G. S. Kumar, M. Raja, S. Parthasarathy, Electrochimica Acta 40 (1995) 285-90.

[17] D. Thompsett, Catalysts for the proton exchange membrane fuel cell, Fuel cell technology handbook. 2003.

[18] Y. Yi, B. D. Lee, S. K. Kim, D. H. Jung, E.M. Jung, S. M. Hwang, S. Y. Choi, D. H. Peck, Journal of Electrochemical Science 11 (2016) 5909-23

[19] J. Zeng, J.Y. Lee, W. Zhou, Applied Catalysis A: General 308 (2006) 99-104.

[20] U.A. Paulus, Z. Veziridis, B. Schnyder, M. Kuhnke, G.G. Scherer, A. J. Wokaun, Journal of Electroanalytical Chemistry 541 (2003) 77-91.

[21] M. Łukaszewski, M. Soszko, A. Czerwiński, International Journal of Electrochemical Science 11 (2016) 4442-69.

[22] T. Binninger, E. Fabbri, R. Kötz, T.j. Schmidt, Journal Electrochemical Society 61 (2014) H121-8.

[23] A. Pozio, M. De Francesco, A. Cemmi , F. Cardellini, L. Giorgi, Journal of Power Sources 105 (2002) 13-9.

[24] M. A. Watanabe, S.Motoo, Journal of Electroanalytical Chemistry and Interfacial Electrochemistry 60 (1975) 267-73.

[25] H. A. Gasteiger, W.Gu, R. Makharia, M. F. Mathias, B. Sompalli, Beginning-of-life MEA performance-efficiency loss contributions, Handbook of fuel cells 2003.

[26] T. Vidaković, M. Christov, K. Sundmacher, Electrochimica Acta 18 (2007) 5606-13.

[27] D. F. Van der Vliet, C. Wang, D. Li, A. P. Paulikas, J. Greeley, R. B. Rankin, D. Strmcnik, D. Tripkovic, N. M. Markovic, V. R. Stamenkovic, Angewandte Chemie 124 (2012) 3193-6.

[28] S. Gamburzev, C. Boyer, A.J. Appleby, Fuel Cells Bulletin 2 (1999) 6-8. 
[29] S. Martin, J.L. Castillo, International Journal of Hydrogen Energy 35 (2010) 10446-10451.

[30] S. Martin, P. L. Garcia-Ybarra, J. L. Castillo, Journal of Power Sources 195 (2010) 2443-9.

[31] S. Martin, B. Martinez-Vazquez, P.L. Garcia-Ybarra, J.L. Castillo, Journal of Power Sources 229 (2013) 179-184.

[32] X. Wang, F.W. Richey, K.H. Wujcik, Y. A. Elabd, Journal of Power Sources 264 (2014) 42-48.

[33] S.M. Alia, G. Zhang, D. Kisailus, D. Li, S. Gu, K. Jensen, Y. Yan, Advanced Functional Materials 20 (2010) 3742-3746

[34] H. Su, T. Jao, O. Barron, B.G. Pollet, S. Pasupathi, Journal of Power Sources 267 (2014) $155-159$.

[35] Y. Nabil, S. Cavaliere, I. A. Harkness, J. D. Sharman, D. J. Jones, J. Rozière, Journal of Power Sources 363 (2017) 20-26.

[36] Y. Nabil-Moreau, S. Cavaliere, I. Harkness, G. Hards, J. Sharman, D. J. Jones, J. Rozière, ECS Transactions 69 (2015) 1221-1226.

[37] A. Esmaeilifar, S. Rowshanzamir,M.H. Eikani, E. Ghazanfari, Energy 35 (2010) 3941-57.

[38] A. Smirnova, U. Kitkamthorn, M. Aindow, T. Lemi, Journal of Power Sources 179 (2008) 532-540.

[39] B. Fang, N.K. Chaudhari, M. Kim, J.H. Kim, J. Yu, Journal of American Chemical Society 131 (2009) 15330-15338.

[40] W. Mróz, B. Budner, W. Tokarz, P. Piela, M.L. Korwin-Pawlowski, Journal of Power Sources 273 (2015) 885-893.

[41] U. Rost, R. Muntean, G. Marginean, C. Merino, R. Diez, N. Vaszilcsin, M. Brodmann, International Journal of Electrochemical Science 11 (2016) 9110-9122.

[42] R. H. Huang, W.K. Chao, R. S. Yu, K. L. Hsueh, F. S. Shieu, Journal of Power Sources 205 (2012) 93-99.

[43] H. Lv, S. Mu, N.Cheng, M. Pan, Applied Catalysis B: Environmental 100 (2010) 190-196.

[44] S. Sharma, B.G.Pollet, Journal of Power Sources 208 (2012) 96-119.

[45] H. Su, S. Liao, Y. Wu, Journal of Power Sources 195 (2010) 3477-3480.

[46] Y. Qiu, H. Zhang, H. Zhong, F. Zhang, International Journal of Hydrogen Energy 38 (2013) 58365844 .

[47] G.S. Avcioglu, B. Ficicilar, A. Bayrakceken, I. Eroglu, International Journal of Hydrogen Energy 40 (2015) 7720-7731.

[48] M. Breitwieser, M. Klingele, B. Britton, S. Holdcroft, R. Zengerle, S. Thiele, Electrochemistry Communications 60 (2015) 168-71.

[49] D. Kaplan, M. Goor, M. Alon, S. Tsizin, L. Burstein, Y. Rosenberg, I. Popov, E. Peled, Journal of Power Sources 306 (2016) 219-225.

[50] G.Y. Chen, C. Wang, Y.J. Lei, J. Zhang, Z. Mao, Z.Q. Mao, J.W. Guo, J. Li, M. Ouyang, International Journal of Hydrogen Energy 42 (2017) 29960-29965.

[51] M. Yaldagard, M. Jahanshah, N. Seghatoleslami, World Journal of Nano Science and Engineering 3 (2014) 121.

[52] X. Cheng, B. Yi, M. Han, J. Zhang, Y. Qiao, J. Yu, Journal of Power Sources 79 (1999) 75-81.

[53] E. Antolini, L. Giorgi, A. Pozio, E. Passalacqua, Journal of Power Sources 77 (1999) 136-142.

[54] G. Sasikumar, J.W. Ihm, H. Ryu, Journal of Power Sources 132 (2004) 11-17.

[55] J. Jiang, B. Yi, Journal of Electroanalytical Chemistry 577 (2005) 107-115.

[56] A. Bayrakceken, A. Smirnova, U. Kitkamthorn, M. Aindow, L. Turker, I. Eroǧlu, C. Erkey, Chemical Engineering Communications 196 (2009) 194-203.

[57] A. Khan, B.K. Nath, J. Chutia, Electrochimica Acta 146 (2014) 171-177.

[58] E. Slavcheva, G. Ganske, G. Topalov, W. Mokwa, U. Schnakenberg, Applied Surface Science 255 (2009) 6479-6486.

[59] X. Wang, F.W. Richey, K.H. Wujcik, R. Ventura, K. Mattson, Y.A. Elabd, Electrochimica Acta 139 (2014) 217-224.

[60] J. Speder, A. Zana, I. Spanos, J.J.K. Kirkensgaard, K. Mortensen, M. Hanzlik, M. Arenz, Journal of Power Sources 261 (2014) 14-22.

[61] G. Zhao, T.S. Zhao, J. Xu, Z. Lin, X. Yan, International Journal of Hydrogen Energy 42 (2017) 33253334.

[62] T.H. Kim, J.Y. Yi, C.Y. Jung, E. Jeong, S.C. Yi, International Journal of Hydrogen Energy 42 (2017) 478485.

[63] C. Ruengkit, N. Tantavichet, Thin Solid Films 636 (2017) 116-126. 
[64] A. Egetenmeyer, I. Radev, D. Durneata, M. Baumgärtner, V. Peinecke, H. Natter, R. Hempelmann, International Journal of Hydrogen Energy 42 (2017) 13649-13660.

[65] D. Zhao, B. Q. Xu, Angewandte Chemie International Edition 45 (2006) 4955-4959.

[66] A. Kongkanand, S. Kuwabata, G. Girishkumar, P. Kamat, Langmuir 22 (2006) 2392-2396.

[67] A. Orfanidi, M.K. Daletou, S.G. Neophytides, Applied Catalysis B: Environmental 106 (2011) 379389.

[68] W. Zhu, D. Ku, J.P. Zheng, Z. Liang, B. Wang, C. Zhang, S. Walsh, G. Au, E.J. Plichta, Electrochimica Acta 55 (2010) 2555-2560.

[69] R. Kou, Y. Shao, D. Wang, M.H. Engelhard, J.H. Kwak, J. Wang, V. V. Viswanathan, C. Wang, Y. Lin, Y. Wang, I.A. Aksay, J. Liu, Electrochemistry Communications 11 (2009) 954-957.

[70] E. Salernitano, L. Giorgi, T. Dikonimos, International Journal of Hydrogen Energy 39 (2014) 1500515016.

[71] S. Huang, P. Ganesan, B.N. Popov, Applied Catalysis B: Environmental 102 (2011) 71-77.

[72] J. Song, G. Li, J. Qiao, Electrochimica Acta 177 (2015) 174-180.

[73] L. I. Sanli, V. Bayram, S. Ghobadi, N. Duzen, S A Gursel, International Journal of Hydrogen Energy 42 (2017) 1085-1092.

[74] R. Singh, M.K. Singh, S. Bhartiya, A. Singh, D.K. Kohli, P.C. Ghosh, S. Meenakshi, P.K. Gupta, International Journal of Hydrogen Energy 42 (2017) 11110-11117.

[75] O. Lori, S. Gonen, L. Elbaz, Journal of Electrochemical Society 164 (2017) F825-F830.

[76] A. Ignaszak, C. Song,W. Zhu, J. Zhang, A. Bauer, R. Baker, V. Neburchilov, S. Ye, S. Campbell. Electrochimica Acta 69 (2012) 397-405.

[77] J.Lobato, H. Zamora, J. Plaza, P. Cañizares, M. A. Rodrigo, Applied Catalysis B: Environmental 198 (2016) 516-524.

[78] S. Shahgaldi, J. Hamelin, Fuel 150 (2015) 645-655.

[79] L. Borchardt, F. Hasché, M. R. Lohe, M. Oschatz, F. Schmidt, E. Kockrick, C. Ziegler,T. Lescouet, B. Büchner, D. Farrusseng, Carbon 50 (2012) 1870.

[80] H.A.Gasteiger, S.S. Kocha , B. Sompalli, F.T. Wagner, Applied Catalysis B: Environmental 56 (2005) 9-35.

[81] B. Wang, Journal of Power Sources 152 (2005) 1-5.

[82] H. Wu, D. Wexler, H. Liu, Material Chemistry Physics 136 (2012) 845-849.

[83] M. Sahoo, S. Ramaprabhu, Energy 119 (2017) 1075-1083.

[84] C. Wang, Z. Lin Chen, A. Wen Tao, H. Zhang, Journal of Electrochemical Energy Conversion and Storage 13 (2016) 21001.

[85] S. Koh, N. Hahn, C. Yu, P. Strasser, Journal of Electrochemical Society 12 (2008) B1281-8.

[86] M. Bele, P. Jovanovič, A. Pavlišič, B. Jozinović, M. Zorko, A. Rečnik, E. Chernyshova, S. Hočevar, N. Hodnik, M. Gaberšček, Chemical Communications 50 (2014) 13124-6.

[87] P. Mani, R. Srivastava, P. Strasser, Journal of Physical Chemistry C 112 (2008) 2770-8.

[88] S. Hong, M. Hou, H. Zhang, Y. Jiang, Z. Shao, B. Yi, Electrochimica Acta 245 (2017) 403-409.

[89] S. Wang, G. Sun, Z. Wu, Q. Xin, Journal of Power Sources 165 (2007) 128-133.

[90] D.J. You, K. Kwon, S.H. Joo, J.H. Kim, J.M. Kim, C. Pak, H. Chang, International Journal of Hydrogen Energy 37 (2012) 6880-6885.

[91] Z.F. Wang, L. Shi, G.Z. Gou, A.P. Fan, C. Xu, L. Zhang, In Advanced Materials and Structural Engineering: Proceedings of the International Conference on Advanced Materials and Engineering Structural Technology (ICAMEST 2015), April 25-26, 2015, Qingdao, China, p. 167. CRC Press, 2016.

[92] L. Pu, H. Zhang, T. Yuan, Z. Zou, L. Zou, X.-M. Li, H. Yang, Journal of Power Sources 276 (2015) 95101.

[93] B. Krishnamurthy, S. Deepalochani, K.S. Dhathathreyan, Fuel Cells 8 (2008) 404-409.

[94] B. Krishnamurthy, S. Deepalochani, International Journal of Hydrogen Energy 34 (2009) 446-452.

[95] B. Krishnamurthy, S. Deepalochani, Journal of Electrochemical Society 4 (2009) 386-395.

[96] S. Matar, H. Liu, Electrochimica Acta 56 (2010) 600-606.

[97] Q. Jiang, Z. Peng, X. Xie, K. Du, G. Hu, Y. Liu, Transactions of Nonferrous Metals Society of China 21 (2011) 127-132.

[98] A.D. Moore, S.M. Holmes, E.P.L. Roberts, RSC Advances 2 (2012) 1669-1674.

[99] X. Zhao, W. Li, Y. Fu, A. Manthiram, International Journal of Hydrogen Energy 37 (2012) 9845-9852. 
[100] J.J. Wang, G.P. Yin, J. Zhang, Z.B. Wang, Y.Z. Gao, Electrochimica Acta 52 (2007) 7042-7050.

[101] C. Chen, C. Chen, C. Chen, F. Chuang, Electrochemistry Communications 9 (2007) 159-163.

[102] M. Yaldagard, M. Jahanshahi, N. Seghatoleslami, Applied Surface Science 317 (2014) 496-504.

[103] R.I. Jafri, N. Rajalakshmi, K.S. Dhathathreyan, S. Ramaprabhu, International Journal of Hydrogen Energy 40 (2015) 4337-4348.

[104] C. Alegre, D. Sebastián, M.E. Gálvez, R. Moliner, M.J. Lázaro, Applied Catalysis B: Environmental 192 (2016) 260-267.

[105] T. Tesfu-Zeru, M. Sakthivel, J.F. Drillet, Applied Catalysis B: Environmental 204 (2017) $173-184$.

[106] M.G. Hosseini, R. Mahmoodi, International Journal of Hydrogen Energy 42 (2017) 10363-10375.

[107] Z.X. Liang, T.S. Zhao, Journal of Physical Chemistry 111 (2007) 8128-8134.

[108] M.A. Scibioh, I. Oh, T. Lim, S. Hong, H.Y. Ha, Applied Catalysis B: Environmental 77 (2008) 373-385.

[109] L. Pu, J. Jiang, T. Yuan, J. Chai, H. Zhang, Z. Zou, X.M. Li, H. Yang, Applied Surface Science 327 (2015) 205-212.

[110] D. Kaplan, L. Burstein, I. Popov, E. Peled, Journal of Electrochemical Society 163 (2016) F1004F1010.

[111] K. Lin, Y. Lu, S. Du, X. Li, H. Dong, International Journal of Hydrogen Energy 41 (2016) 7622-7630.

[112] F. Alcaide, G. Álvarez, P.L. Cabot, R. Genova-Koleva, H.J. Grande, O. Miguel, Electrochimica Acta 231 (2017) 529-538.

[113] K. Han, J. Lee, H. Kim, Electrochimica Acta 52 (2006) 1697-1702.

[114] Z.-P. Sun, X.-G. Zhang, Y.-Y. Liang, H. Tong, R.L. Xue, S.D. Yang, H.-L. Li, Journal of Electroanalytical Chemistry 633 (2009) 1-6.

[115] M. Carmo, M. Linardi, Applied Catalysis A: General 355 (2009) 132-138.

[116] F. Luo, S. Liao, D. Chen, Journal of Energy Chemistry 22 (2013) 87-92.

[117] Z. Liu, Q. Shi, F. Peng, H. Wang, R. Zhang, H. Yu, Electrochemistry Communications 16 (2012) 73-76.

[118] H. Sun, L. Qi, X. Jiang, G. Fu, L. Xu, D. Sun, Z. Gu, Y. Tang, New Journal of Chemistry 41 (2017).

[119] H. Gharibi, M. Amani, H. Pahlavanzadeh, M. Kazemeini, Electrochimica Acta 97 (2013) $216-225$.

[120] Y. Li, C. Liu, Y. Liu, B. Feng, L. Li, H. Pan, W. Kellogg, D. Higgins, G. Wu, Journal of Power Sources 286 (2015) 354-361.

[121] P.P. Patel, M.K. Datta, P.H. Jampani, D. Hong, J.A. Poston, A. Manivannan, P.N. Kumta, Journal of Power Sources 293 (2015) 437-446.

[122] L. M. Zhang, X. L. Sui, L. Zhao, J.J. Zhang, D. M. Gu, Z. B. Wang, Carbon 108 (2016) 561-567.

[123] H. Gao, L. He, Y. Zhang, S. Zhang, L. Wang, lonics (Kiel) 23 (2017) 435-442.

[124] M. K. Jeon, K. R. Lee,W. S. Lee, H. Daimon, A. Nakahara, S. I. Woo, Journal of Power Sources 185 (2008) 927-931.

[125] L. Giorgi, E. Salernitano, T. D. Makris, S. Gagliardi, V. Contini, M. De Francesco, International Journal of Hydrogen Energy 39 (2014) 21601-21612.

[126] H. D. Jang, S. K. Kim, H. Chang, J. Choi, B. Cho, E. Hee, J. Choi Huang, Carbon 93 (2015) 869-877.

[127] J. Chang, L. Feng, C. Liu , W. Xing, X. Hu, Energy \& Environmental Science 7 (2014) 1628-1632.

[128] J. Chang, L. Feng, C. Liu, W. Xing, ChemSusChem 8 (2015) 3340-3347.

[129] J. Chang, L. Feng, K. Jiang, H. Xue, W. B. Cai, C. Liu, W. Xing, Journal of Materials Chemistry A 47 (2016) 18607-18613.

[130] L. Feng, K. Li, J. Chang, C. Liu, W. Xing, Nano Energy 15 (2015) 462-9.

(C)2019 by the authors; licensee IAPC, Zagreb, Croatia. This article is an open-access article distributed under the terms and conditions of the Creative Commons Attribution license (http://creativecommons. org/licenses/by/4.0/) 